Purdue University

Purdue e-Pubs

2011

\title{
Local Heat Transfer Distribution and Effect of Instabilities During Flow Boiling in a Silicon Microchannel Heat Sink
}

Tailian Chen

Gonzaga University

S V. Garimella

Purdue University, sureshg@purdue.edu

Follow this and additional works at: http://docs.lib.purdue.edu/coolingpubs

Chen, Tailian and Garimella, S V., "Local Heat Transfer Distribution and Effect of Instabilities During Flow Boiling in a Silicon Microchannel Heat Sink" (2011). CTRC Research Publications. Paper 152.

http://dx.doi.org/10.1016/j.ijheatmasstransfer.2011.04.012

This document has been made available through Purdue e-Pubs, a service of the Purdue University Libraries. Please contact epubs@purdue.edu for additional information. 


\title{
Local Heat Transfer Distribution and Effect of Instabilities during Flow Boiling in a Silicon Microchannel Heat Sink ${ }^{\dagger}$
}

\author{
Tailian Chen ${ }^{1}$ and Suresh V. Garimella ${ }^{2}$ \\ ${ }^{1}$ Department of Mechanical Engineering, Gonzaga University \\ Spokane, WA 99258-0026 \\ ${ }^{2}$ Cooling Technologies Research Center, an NSF IUCRC \\ School of Mechanical Engineering and Birck Nanotechnology Center, Purdue University \\ West Lafayette, IN 47907-2088
}

\begin{abstract}
Flow boiling of the perfluorinated dielectric fluid FC-77 in a silicon microchannel heat sink is investigated. The heat sink contains 60 parallel microchannels each of $100 \mu \mathrm{m}$ width and $389 \mu \mathrm{m}$ depth. Twenty-five evenly distributed temperature sensors in the substrate yield local heat transfer coefficients. The pressure drop across the channels is also measured. Experiments are conducted at five flow rates through the heat sink in the range of 20 to $80 \mathrm{ml} / \mathrm{min}$ with the inlet subcooling held at $26 \mathrm{~K}$ in all the tests. At each flow rate, the uniform heat input to the substrate is increased in steps so that the fluid experiences flow regimes from single-phase liquid flow to the occurrence of critical heat flux (CHF). In the upstream region of the channels, the flow develops from single-phase liquid flow at low heat fluxes to pulsating two-phase flow at high heat fluxes during flow instability that commences at a threshold heat flux in the range of $30.5-62.3 \mathrm{~W} / \mathrm{cm}^{2}$ depending on the flow rate. In the downstream region, progressive flow patterns from bubbly flow, slug flow, elongated bubbles or annular flow, alternating wispy-annular and churn flow, and wall dryout at highest heat fluxes are observed. As a result, the heat transfer coefficients in the downstream region experience substantial variations over the entire heat flux range, based on which five distinct boiling regimes are identified. In contrast, the heat transfer coefficient midway along the channels remains relatively constant over the heat flux range tested. Due to changes in flow patterns during flow instability, the heat transfer is enhanced both in the downstream region (prior to extended wall dryout) and in the upstream region. A previous study by the authors found no effect of instabilities during flow boiling in a heat sink with larger microchannels (each $300 \mu \mathrm{m}$ wide and $389 \mu \mathrm{m}$ deep); it appears therefore that the effect of instabilities on heat transfer is amplified in smaller-sized channels. While CHF increases with increasing flow rate, the pressure drop across the channels has only a minimal
\end{abstract}

\footnotetext{
${ }^{\dagger}$ The experiments of this work were performed when the lead author was a Post-doctoral Researcher at Purdue University.
} 
dependence on flow rate once boiling is initiated in the microchannels, and varies almost linearly with increasing heat flux.

Keywords: Flow boiling, microchannels, boiling regimes, flow instability, electronics cooling

\section{Nomenclature}

$A_{b} \quad$ microchannel heat sink base area $\left(\mathrm{m}^{2}\right)$

$\Delta \mathrm{P} \quad$ pressure drop $(\mathrm{Pa})$

h heat transfer coefficient $\left(\mathrm{W} / \mathrm{m}^{2}-\mathrm{K}\right)$

$\mathrm{N}$ number of data points

$\mathrm{k} \quad$ silicon thermal conductivity $(\mathrm{W} / \mathrm{m}-\mathrm{K})$

$\dot{\mathrm{q}}_{\text {fluid }} \quad$ heat transfer rate to the fluid (W)

$\dot{\mathrm{q}}_{\text {loss }} \quad$ heat loss $(\mathrm{W})$

$\dot{\mathrm{q}}_{\text {total }} \quad$ total heat dissipated by the heating elements (W)

$\mathrm{R} \quad$ electrical resistance of heating elements $(\Omega)$

$t_{b} \quad$ thickness from the temperature sensors to the microchannel bottom (m)

$\mathrm{T}_{\mathrm{b}} \quad$ temperature measured by temperature sensors in the heat sink base $\left({ }^{\circ} \mathrm{C}\right)$

$\mathrm{T}_{\mathrm{w}} \quad$ temperature at the bottom of microchannels $\left({ }^{\circ} \mathrm{C}\right)$

$\mathrm{V} \quad$ voltage drop across temperature sensors (V)

Greek symbols

$\sigma_{\Delta \mathrm{P}} \quad$ standard deviation of pressure drop (Pa) 


\section{Background}

Two-phase flow in microchannels provides higher performance than in single-phase operation while maintaining the wall temperature relatively uniform, and offers an attractive alternative for the cooling of high-power electronics. Although microchannel heat sinks have been extensively studied [1,2], understanding of two-phase thermal transport phenomena in microchannels is still limited due to their complexity.

A number of studies have discussed the differences in flow boiling between small and large channels; a quantitative criterion was recently proposed for delineating micro- and macroscale behavior in twophase flow through microchannels [3]. For flow boiling in large channels, both convective and nucleate boiling heat transfer are considered important [4] and the overall heat transfer coefficient is a function of mass flow rate, heat flux, and vapor quality [5]. In contrast, the heat transfer coefficient during flow boiling in microchannels can be well predicted by correlations proposed for nucleate boiling heat transfer [6], and was found to be independent of mass flow rate and to decrease with increasing local vapor quality as the flow propagates downstream [7,8,9]. Piasecka et al. [10] showed that initiation of boiling in a narrow channel causes a sharp drop in the wall temperature and the boiling extends upstream as the heat flux is increased. In an investigation of flow boiling of refrigerant R-134a in a microchannel cold plate, Bertsch et al. [11] found that the heat transfer coefficient varies significantly with refrigerant inlet quality and mass flow rate, but varies only slightly with saturation pressure for the range of values investigated.

Systematic investigations of the effects of channel size on flow boiling in microchannels have also been reported. In a study of the effects of channel size on flow boiling in 400- $\mu \mathrm{m}$ deep microchannels of different widths ranging from 100 to $5850 \mu \mathrm{m}$, Harirchian and Garimella [12, 13] observed that flow regimes in microchannels of width $400 \mu \mathrm{m}$ and larger are similar, with nucleate boiling being dominant in these channels over a wide range of heat flux. However, flow regimes in microchannels of width 100 and $250 \mu \mathrm{m}$ were different, and bubble nucleation at the walls was suppressed at a relatively low heat flux. Their heat transfer measurements showed that for microchannels of width $400 \mu \mathrm{m}$ and greater, the heat transfer coefficients corresponding to a fixed wall heat flux, as well as the boiling curves, are independent of channel size. Also, heat transfer coefficients and boiling curves are independent of mass flux in the nucleate boiling region for a fixed channel size, but are affected by mass flux as convective boiling begins to dominate. Karayiannis et al. [14] performed a study of flow boiling in tubes of hydraulic diameters ranging from 0.52 to $4.26 \mathrm{~mm}$. They observed that boiling in the $0.52-\mathrm{mm}$ tube was significantly more complex than that in larger tubes tested. Within a certain range of heat flux, the boiling heat transfer coefficient in the $0.52-\mathrm{mm}$ tube was measured to decrease with increasing heat flux. 
Flow instabilities during flow boiling in microchannels have also been investigated $[15,16,17,18]$. Flow instability was found to reduce boiling heat transfer coefficients [16] and resulted in severe nonuniformity in wall temperature [18]. High-speed visualizations of flow boiling of FC-77 in 389- $\mu$ m wide and 389- $\mu \mathrm{m}$ deep microchannels performed by Chen and Garimella [19] showed that as flow instability sets in, the flow patterns change from bubble slugs and elongated bubbles to intermittent wispy-annular and churn flow in the downstream region of microchannels; the single-phase flow near the inlet is replaced by pulsating two-phase flow. This flow instability also results in stronger fluctuations in the pressure drop across microchannels, but its effect on heat transfer is insignificant until the higher heat fluxes at which extended wall dryout occurs. Gillot et al. [20] found that the exit vapor quality must be below 0.3 to avoid the occurrence of flow instability during flow boiling of FC-72 in a microchannel heat sink.

A generally accepted correlation to predict flow boiling heat transfer in microchannels is not available yet. Chen and Garimella [21] found that the measured boiling heat transfer coefficients in a microchannel heat sink agree reasonably well with predictions from the Cooper correlation [22] proposed for nucleate boiling. From a database of 3899 data points compiled from 14 studies in the literature covering 12 different wetting and non-wetting fluids, hydraulic diameters ranging from 0.16 to $2.92 \mathrm{~mm}$, and confinement numbers from 0.3 to 4.0, Bertsch et al. [23] developed a composite correlation that includes nucleate boiling and convective heat transfer terms while accounting for the effect of bubble confinement in small channels. The correlation predicts the data within a mean absolute error of less than $30 \%$.

In this work, local heat transfer distributions during flow boiling in microchannels are used to facilitate an understanding of the effect of instabilities on thermal performance. Experiments are performed with the perfluorinated dielectric fluid, FC-77, in a silicon microchannel heat sink of dimensions $12.7 \mathrm{~mm} \times 12.7 \mathrm{~mm}$ containing 60 parallel microchannels (each $100 \mu \mathrm{m}$ wide and $389 \mu \mathrm{m}$ deep). Twenty-five semiconductor heating elements in the substrate (each approximately $2.54 \mathrm{~mm} \times 2.54$ $\mathrm{mm}$ ) provide heat to the fluid in the microchannels. At the center of each heating element is a diode temperature sensor that measures the local wall temperature and yields the local heat transfer coefficient. The pressure drop was measured across the full length of the microchannel heat sink. Comparison with results obtained previously for flow boiling in larger microchannels provides an understanding of the effect of channel dimensions on the impact of instabilities.

\section{Experiments}

\subsection{Test Loop}

A schematic diagram of the test loop is shown in Figure 1. A magnetically coupled gear pump drives the fluid through the closed loop and a precision flow meter (McMillan Company, model S-114) monitors 
the flow rate. A preheater before the test section controls the degree of fluid inlet subcooling and a heat exchanger installed after the test section rejects the heat added in the test section to air through a fancooled heat sink. The two degassing ports shown in Figure 1 are used to degas the liquid in the reservoir and evacuate air from the test loop. After the fluid is fully degassed, it is charged into the evacuated test loop. The pressure in the outlet manifold of the test section is maintained at atmospheric pressure by the bellows-like reservoir. Details of the degassing scheme and the test procedures are available in [24]. The boiling point of the fully degassed perfluorinated dielectric liquid, FC-77, is $97^{\circ} \mathrm{C}$ at a pressure of $1 \mathrm{~atm}$.

The experiments were performed at five flow rates in the range of 20 to $80 \mathrm{ml} / \mathrm{min}$ (at room temperature), corresponding to a mass flux range of 253.7 to $1015.0 \mathrm{~kg} / \mathrm{s}-\mathrm{m}^{2}$. The (subcooled) fluid temperature at the inlet was maintained at $71 \pm 1.0^{\circ} \mathrm{C}$ for all flow rates. For each flow rate, experiments were started with a low heat input at which single phase flow exists along the length of the microchannels. The heat input was then increased in steps and data were obtained when the flow and temperatures reached a steady state at each heat input. The experiments were terminated for each flow rate when the temperature sensor near the exit detected a sharp increase in wall temperature, which indicated the occurrence of $\mathrm{CHF}$ in the microchannels.

\subsection{Test Section}

Figure 2(a) is a photograph of the printed circuit board (PCB) with the silicon test die at the center. The mounting details of the silicon die on the PCB are shown in Figure 2(b). The $12.7 \mathrm{~mm}$ by $12.7 \mathrm{~mm}$ silicon die, fabricated and provided by Delphi Electronics \& Safety, has 25 heating elements (doped silicon wells), each of approximate size $2.54 \mathrm{~mm}$ by $2.54 \mathrm{~mm}$ and nominal resistance of $26.4 \Omega$ at room temperature. A diode temperature sensor (consisting of five $p-n$ junctions in series) is fabricated at the center of each heating element. A uniform heat input was provided by connecting the 25 heating elements in parallel to a DC power supply. Figure 3(a) shows the arrangement of the 25 heating elements (U1 to U25) with the flow going from right to left. Sixty parallel microchannels, each $100 \pm 0.1 \mu \mathrm{m}$ wide and $389 \pm 1.5 \mu \mathrm{m}$ deep, were machined by saw-cutting the silicon die on the opposite side of the heating elements and temperature sensors. The width of the fins between the microchannels is $100 \mu \mathrm{m}$. A photograph of the test section assembly with the test die PCB sandwiched between the substrate and the polycarbonate cover is shown in Figure 3(b). The temperature sensors and heating elements on the test die were wired to the extension PCB in the assembly for ease of instrumentation. Further details of the test section assembly are available in [19]. Two thermocouples inserted into the inlet and outlet manifolds of the heat sink measure the local fluid temperatures. A differential pressure transducer is used to measure pressure drop across the microchannels. 
The voltage drop across the diode sensor biased at a constant electrical current has a temperature dependence of approximately $-2 \mathrm{mV} /{ }^{\circ} \mathrm{C}$. The exact voltage-temperature relationship for each temperature sensor (five diodes in series) was calibrated by placing the test section assembly in a controlled, uniformtemperature oven. Five thermocouples positioned at five different locations on the test section assembly monitored the temperature. The test section assembly was considered to have reached a thermal steady state when the readings from all five thermocouples were identical and remained unchanged with time. The voltages across the 25 temperature sensors and the resistances of the 25 heating elements were simultaneously recorded at this time. Such calibration tests were conducted over a range of oven temperatures from room temperature $\left(23^{\circ} \mathrm{C}\right)$ up to $105^{\circ} \mathrm{C}$. The voltage-temperature relationships for all 25 temperature sensors so obtained are represented by $\mathrm{V}=-0.0104 \mathrm{~T}_{\mathrm{b}}\left({ }^{\circ} \mathrm{C}\right)+3.5125$, as illustrated in Figure 4(a). This relationship was subsequently used in the experiments to determine the temperature, $\mathrm{T}_{\mathrm{b}}$, from the measured voltage drop, $\mathrm{V}$, across each temperature sensor. This calibration also indicated that the resistance of each heating element increases with temperature, at a rate of approximately $2 \Omega$ for a temperature increase of $100^{\circ} \mathrm{C}$ as illustrated in Figure 4(b); the curve-fit for each heating element was used in calculating the heat generated by the heating elements.

\section{Data Reduction and Uncertainty Analysis}

An energy balance can be written for each of the 25 heating elements as

$$
\dot{\mathrm{q}}_{\text {total }}=\dot{\mathrm{q}}_{\text {fluid }}+\dot{\mathrm{q}}_{\text {loss }}
$$

in which $\dot{\mathrm{q}}_{\text {total }}$ is the total heat generation calculated directly from the applied voltage $\mathrm{V}$ and the resistance of the heating element $\mathrm{R}$; $\dot{\mathrm{q}}_{\text {fluid }}$ is the heat transferred to the fluid. $\dot{\mathrm{q}}_{\text {loss }}$ is the heat loss obtained by measuring the heat input to the assembled test section at each temperature before the test loop was charged with fluid as described in [19]; a relationship is thus obtained between the heat loss and the heat sink base temperature, $\mathrm{T}_{\mathrm{b}}$, for each heating element. For instance, the heat loss for the heating element $\mathrm{U} 3$ is represented by $\dot{\mathrm{q}}_{\text {loss }}=0.1229 \mathrm{~T}_{\mathrm{b}}-2.7821$. This heat loss-temperature relationship is used in Equation (1) to determine the heat transferred to the fluid, $\dot{\mathrm{q}}_{\text {fluid }}$, during the boiling experiments. A local heat transfer coefficient, $h$, is calculated as

$$
\mathrm{h}=\dot{\mathrm{q}}_{\text {fluid }} /\left(\mathrm{T}_{\mathrm{w}}-\mathrm{T}_{\mathrm{sat}}\right) \mathrm{A}_{\mathrm{b}}
$$

In Equation (2), $\mathrm{A}_{\mathrm{b}}$ is the heating element area, $0.0645 \mathrm{~cm}^{2}$, which is $1 / 25^{\text {th }}$ of the total heat sink base area. Due to the pressure drop in the microchannels, the local saturation temperature $T_{\text {sat }}$ in Equation (2) decreases in the flow direction. A linear pressure drop from the inlet to the exit of the microchannels is assumed for obtaining the local pressure and thus the local saturation temperature $T_{\text {sat }}$ in the 
microchannels. The wall temperature $\mathrm{T}_{\mathrm{w}}$ is obtained by correcting the temperature measured at the base of the microchannel substrate $\mathrm{T}_{\mathrm{b}}$ using

$$
\mathrm{T}_{\mathrm{w}}=\mathrm{T}_{\mathrm{b}}-\left(\dot{\mathrm{q}}_{\text {fluid }} \mathrm{t}_{\mathrm{b}}\right) /\left(\mathrm{k} \mathrm{A}_{\mathrm{b}}\right),
$$

in which $t_{b}$ is the distance from the heat sink base to the bottom of the microchannels $(=0.373 \mathrm{~mm})$ and $\mathrm{k}$ is the silicon thermal conductivity.

Uncertainties in the measured quantities are estimated to be \pm 2.5 to $10.0 \%$ in the flow rate over the range considered, and 0.69 to $8.62 \%$ in the pressure drop measurements for measured values in the range of 2000 to $25000 \mathrm{~Pa}$; the larger uncertainties occur at the smaller measured values. The wall temperature uncertainty comes from calibration of the temperature sensors and from correction for the temperature drop from the heat sink base as in Equation (3). The wall temperature uncertainty is estimated to be $\pm 0.2^{\circ} \mathrm{C}$. Uncertainties in the heat transfer coefficient arise from those in the determination of heat transfer rate into the microchannels and the wall temperature measurements. Following the procedure described by Kline and McClintock [25], the uncertainty in heat transfer coefficient is estimated to be in the range of 2 to $12 \%$, with the larger uncertainties occurring at the lower heat fluxes.

\section{Results and Discussion}

\subsection{Initiation of Boiling}

Figure 5 shows the wall temperatures $\mathrm{T}_{\mathrm{w}}$ measured from the five temperature sensors located along the midline of the heat sink in the heat flux range at the lower end $\left(<42 \mathrm{~W} / \mathrm{cm}^{2}\right)$ over which transition from single-phase to two-phase flow occurs in the microchannels at the flow rate of $60 \mathrm{ml} / \mathrm{min}$; $\mathrm{x} / \mathrm{L}$ in the figure represents the location of the temperature sensors with $\mathrm{x} / \mathrm{L}=0.1$ being nearest to the inlet and $\mathrm{x} / \mathrm{L}$ $=0.9$ nearest to the exit. This flow rate corresponds to a velocity of $0.43 \mathrm{~m} / \mathrm{s}$ and a Reynolds number of 93 during single-phase flow through the microchannel. Based on the streamwise heat transfer characteristics measured, the microchannel heat sink is categorized into three regions: the upstream region corresponding to measurements from the temperature sensors at $\mathrm{x} / \mathrm{L}=0.1$ and 0.3 , the middle region to the sensor at $x / L=0.5$, and the downstream region to those at $x / L=0.7$ and 0.9 .

The experiment was started at a very low heat input at which single-phase flow exists throughout the length of the microchannels. As the heat flux is increased to $34 \mathrm{~W} / \mathrm{cm}^{2}$ (marked 'A' in Figure 5), the flow throughout the microchannels still remains a single-phase liquid. A small increase in heat flux from this point $\left(34 \mathrm{~W} / \mathrm{cm}^{2}\right)$ leads to initiation of boiling in the microchannels with an associated sharp drop in wall temperatures in the downstream region $(\mathrm{x} / \mathrm{L}=0.7,0.9)$ and in the middle region $(\mathrm{x} / \mathrm{L}=0.5)$. This

indicates that, upon initiation, boiling has penetrated upstream beyond the midway point of the 
microchannels so that the two-phase flow in the downstream region has entered into a higher-level flow pattern (i.e., much-elongated bubbles). To investigate the two-phase heat transfer spanning the entire spectrum of flow patterns (i.e., from bubbly flow to CHF) in the downstream region after boiling initiation, the heat flux is decreased manually (by reducing the applied voltage) to approximately 27 $\mathrm{W} / \mathrm{cm}^{2}$ (labeled ' $\mathrm{B}$ ' in Figure 5) at which bubbly flow exists in the downstream region; the experiment was then continued by incrementing the heat flux (from that at ' $\mathrm{B}$ '). The chronological order in which the heat input was applied in the experiments is illustrated in Figure 5(b) using the temperatures at $\mathrm{x} / \mathrm{L}=0.9$. It is noted in Figure 5(a) that the wall temperatures measured from the temperature sensors upstream (x/L $=0.1,0.3)$ prior to and after initiation of boiling in the downstream region are the same, which indicates that the flow in the upstream region remains single-phase liquid flow after the initiation of boiling in the downstream region.

It is also noted in Figure 5 that the streamwise temperature non-uniformity is significantly reduced upon the initiation of boiling in the microchannels. This reduction in wall temperature non-uniformity is also illustrated in Figure 6(a) and Figure 6(b) where all 25 wall temperatures across the heat sink are shown prior to and after the establishment of boiling at the flow rate $60 \mathrm{ml} / \mathrm{min}$ and an approximate heat flux $34 \mathrm{~W} / \mathrm{cm}^{2}$. Figure 6(c) shows the significant increase in the wall temperatures in the downstream region of the microchannels when $\mathrm{CHF}$ is reached, as will be discussed later.

\subsection{Streamwise Boiling Characteristics}

Wall temperatures measured at the flow rate of $60 \mathrm{ml} / \mathrm{min}$ over the heat fluxes ranging from the initiation of boiling to the occurrence of CHF in the microchannels are shown in Figure 7(a); the corresponding local heat transfer coefficients in the downstream region $(\mathrm{x} / \mathrm{L}=0.7,0.9)$ and in the middle region $(x / L=0.5)$ are presented in Figure $7(b)$. It is noted in Figure 7(a) that the wall temperatures measured at $\mathrm{x} / \mathrm{L}=0.1$ and 0.3 at low heat fluxes increase linearly with increasing heat flux during the single-phase flow. As the heat flux is increased to approximately $50.7 \mathrm{~W} / \mathrm{cm}^{2}$ (labeled ' $\mathrm{Q}$ ' in the figure), a decrease in the slope of the temperatures is observed, which indicates an enhanced heat transfer rate. As detailed in next section, this heat transfer enhancement in the upstream region is attributed to the change from single-phase flow to pulsating two-phase flow when flow instability commences at the heat flux of $50.7 \mathrm{~W} / \mathrm{cm}^{2}$ at this flow rate $(60 \mathrm{ml} / \mathrm{min})$.

Figure $7(\mathrm{~b})$ shows that the heat transfer coefficient in the middle region $(\mathrm{x} / \mathrm{L}=0.5)$ remains almost constant over the entire heat flux range. Visual observation indicated that the flow in this region is chaotic, with a mixture of newly-nucleated bubbles and vapor slugs superimposed by flow reversal. In contrast, the heat transfer coefficients in the downstream region $(x / L=0.7,0.9)$ vary substantially over the heat flux range. At the lowest heat fluxes, the heat transfer coefficients in this downstream region 
increase within a narrow range of heat flux and then begin to decrease with increasing heat flux before the heat flux labeled as ' $Q$ ' in the figure is reached. As the heat flux is increased further, the heat transfer coefficient remains constant until a heat flux of approximately $72 \mathrm{~W} / \mathrm{cm}^{2}$ (marked ' $\mathrm{B}$ ' in the figure). As the heat flux is increased beyond this value, the heat transfer coefficients decrease monotonically until a sharp decrease is observed at $86.3 \mathrm{~W} / \mathrm{cm}^{2}$, indicative of the occurrence of CHF. A detailed discussion of the heat transfer near the exit $(\mathrm{x} / \mathrm{L}=0.9)$ over the entire heat flux range is provided in next section.

\subsection{Boiling Regimes near the Exit}

Heat transfer coefficients near the exit corresponding to the measurements from the temperature sensor at $\mathrm{x} / \mathrm{L}=0.9$ are presented in Figure 8 for the five flow rates. The heat transfer coefficient varies substantially over the heat flux range for each flow rate; five distinct boiling regimes labeled 'a' through 'e' can be delineated, as shown in the figure.

\subsubsection{Boiling Regime ' $a$ '}

Boiling regime ' $a$ ' represents the initiation of boiling at the lowest heat fluxes at each flow rate. Bubbles nucleate in the downstream region of the channels and exit with little or no wall confinement. In this regime, heat transfer coefficients increase with increasing heat flux due to the increase in bubble nucleation density and growth rate. However, this regime covers only a narrow heat flux range at each flow rate.

\subsubsection{Boiling Regime ' $b$ '}

As the heat flux is increased past the narrow range of regime ' $a$ ' at each flow rate, the heat transfer coefficients decrease with increasing heat flux, in the regime marked ' $b$ ' in Figure 8. Figure 9 shows the flow patterns near the exit of the microchannels in the boiling regimes ' $a$ ' and ' $b$ ': successive occurrence of bubbly flow, slug flow, elongated slugs, and then annular flow is observed. Vapor slugs are formed from individual growing bubbles confined by channel walls. As the vapor slugs travel downstream, they become elongated due to continued liquid evaporation and merging with newly-nucleated bubbles. Formation of annular flow is a result of elongation and merging of vapor slugs. In contrast to this behavior from the small channels in this study, vapor slugs during flow boiling in microchannels of a larger size (389 $\mu \mathrm{m}$ wide and $389 \mu \mathrm{m}$ deep) resulted from bubble coalescence; in these larger channels, the heat transfer coefficient was found to increase with increasing heat flux over a much larger heat flux range as well [19]. 
The decrease in heat transfer coefficient with increasing heat flux observed here was also reported in $[7,8]$, and the behavior was attributed to a large local vapor quality at a higher heat flux. While the physical mechanism responsible for the decrease in heat transfer coefficient in regime ' $b$ ' warrants further investigation, Kandlikar [26] suggested that formation of elongated bubbles and their passage over the microchannel walls have similarities to the bubble ebullition cycle in pool boiling; furthermore, he proposed that wall dryout occurs during the passage of elongated bubbles. For slug flow in microchannels, Jacobi and Thome [27] and Thome and Consolini [28] suggested that liquid thin film evaporation is the dominant heat transfer mode.

Within the heat flux range of the boiling regimes ' $a$ ' and ' $b$ ' for each flow rate, the flow is stable throughout the microchannels without any noticeable flow reversal; in the upstream region, single-phase liquid flow persists, and two-phase flow develops smoothly in the downstream region as the heat flux is increased.

\subsubsection{Two-Phase Flow with Instabilities (Regime 'c')}

In contrast to the decrease in heat transfer coefficients with increasing heat flux in the boiling regime ' $b$ ', the heat transfer coefficients in the boiling regime ' $c$ ' tend to remain relatively constant, which suggests a different heat transfer mechanism. Flow instabilities are responsible for the transition from the boiling regime ' $b$ ' to the boiling regime ' $c$ '. As flow instabilities occur, the flow patterns both downstream and upstream are dramatically changed. The flow in the upstream region is intermittently reversed and alternates with time between reversed flow and non-reversed flow. Such flow reversals were visually observed and documented by the authors in [19] via high-speed visualization. The corresponding instabilities were also reflected as sharp increases in the magnitude of fluctuations recorded in the pressure drop across the microchannels. Stronger instabilities at higher heat fluxes result in bubbles being pushed back into the inlet plenum during the period of reversed flow; as a result, the flow upstream is changed to pulsating two-phase flow. Corresponding to the alternating reversed and non-reversed flow in the upstream region, the flow in the downstream region alternates with time between wispy-annular flow and churn flow. As detailed in [19], the flow reversal in the upstream region causes a periodic change in flow rate in the downstream region of the microchannels. The periodic change in flow rate downstream at a constant heat input leads to the alternating wispy-annular and churn flow; the vapor quality in the former is much higher than that in the latter flow pattern. The photograph in Figure 10, captured at a heat flux of $65 \mathrm{~W} / \mathrm{cm}^{2}$ and flow rate of $60 \mathrm{ml} / \mathrm{min}$, shows the vapor cores in the microchannels during the wispy-annular flow; the liquid film on the channel walls breaks up into liquid patches that may coil up into liquid droplets. Figure 11(a) presents the pressure drop measurements over a period of time (at four heat flux levels and a flow rate of $60 \mathrm{ml} / \mathrm{min}$ ) showing the pressure drop 
fluctuations before and after the commencement of flow instabilities in the microchannels. The standard deviations of the fluctuations in pressure drop, defined as

$$
\sigma_{\Delta P}=\sqrt{\frac{\sum_{i=1}^{N}\left(\Delta p_{i}-\overline{\Delta p}\right)^{2}}{N}}
$$

at the five flow rates are presented in Figure 11(b) over the heat flux range after boiling is established in the microchannels. As seen in Figure 11(b), at low heat fluxes, the standard deviations are minimal and nearly the same for all five flow rates. As the heat flux is increased to a threshold heat flux value for each flow rate, the standard deviations increase monotonically with increasing heat flux indicating that flow instabilities have commenced, and their magnitudes become stronger as the heat flux is increased.

To further illustrate the effect of flow instability, Figure 12 shows the heat transfer coefficients near the exit $(\mathrm{x} / \mathrm{L}=0.9)$ and the corresponding wall temperatures near the inlet $(\mathrm{x} / \mathrm{L}=0.1)$ for all the five flow rates. For the results at each flow rate, 'Q' marks the heat flux at which a decrease in the slope of the wall temperature near the inlet $(\mathrm{x} / \mathrm{L}=0.1)$ is observed; this is also simultaneously the starting point (lower bound of regime ' $c$ ') from which the heat transfer coefficients near the exit $(\mathrm{x} / \mathrm{L}=0.9)$ tend to a nearconstant value. For instance, at the flow rate of $60 \mathrm{ml} / \mathrm{min}$, the heat flux at this point ' $\mathrm{Q}$ ' is $50.7 \mathrm{~W} / \mathrm{cm}^{2}$. Figure 12 shows that this transition heat flux ' $Q$ ' is in the range of $30.5-62.3 \mathrm{~W} / \mathrm{cm}^{2}$ for the five flow rates. An examination of Figure 11(b) reveals that this heat flux is also the value at which the flow instability commences at this flow rate. It is therefore concluded that the flow instabilities enhance heat transfer both in the upstream region and in the downstream region as a result of changes in the flow patterns. The enhancement in heat transfer in the upstream region is seen from the decrease in the slope of wall temperatures in Figure 12. Since the inlet subcooling would keep the upstream region in the single-phase regime, the heat transfer enhancement in this region is primarily attributed to the near-wall turbulence induced by the pulsating two-phase flow. In the downstream region, the enhancement is manifested as the near-constant heat transfer coefficients that otherwise would decrease with an increase in heat flux.

In comparison to the results in this study for the small microchannels, flow boiling in larger microchannels (each $389 \mu \mathrm{m}$ wide and $389 \mu \mathrm{m}$ deep) [19] showed that the heat transfer was not noticeably affected when the instability occurs. It is clear that the channel size has an important role in determining the effect of instabilities on heat transfer. Essentially, the effect of instabilities on heat transfer depends on how the flow pattern is affected. For the $100 \mu \mathrm{m}$-wide channels in the present work, annular or elongated-slug flow dominates near the exit before the occurrence of instability. As the heat flux is increased, the elongated bubbles are further elongated with a corresponding detrimental effect on heat transfer as observed in regime ' $b$ '. As instabilities set in, this flow pattern is changed to alternating churn and wispy flow, with a corresponding improvement in heat transfer performance as discussed with 
respect to regime 'c'. For the $389 \mu$ m-wide channels previously studied [19], the flow pattern is dominated by bubbles (newly nucleated bubbles and bubble slugs formed from agglomeration of bubbles nucleated upstream) due to the larger channel size. This leads to the measured increase in heat transfer coefficient with increasing heat flux before instabilities occur. When instabilities do set in, the increased heat transfer is retained until extended wall dryout (at higher heat flux).

\subsubsection{Channel Dryout (Regimes 'd' and 'e')}

As seen in Figure 8, the boiling regime 'd' differs from regime ' $c$ ' in that the heat transfer coefficients decrease monotonically with increasing heat flux until regime ' $\mathrm{e}$ ' is reached, in which there is a sharp decrease in heat transfer coefficient. As a result of stronger flow reversal in the upstream region at a higher heat flux as shown by the increased pressure drop fluctuations in Figure 11, the time interval for the wispy-annular flow increases and momentary wall dryout or depletion of liquid occurs in the downstream region of microchannels. The extended wall dryout is responsible for the decrease in heat transfer coefficients with increasing heat flux in the boiling regime ' $d$ '. It is noted in Figure 7(b) that the heat transfer coefficients at $\mathrm{x} / \mathrm{L}=0.9$ are lower than those at $\mathrm{x} / \mathrm{L}=0.7$ due to the larger degree of wall dryout nearer the exit.

For each flow rate, the experiment was terminated when a sharp increase in the wall temperature was detected downstream $(x / L=0.9,0.7)$ for a small increase in heat flux. Such a sharp increase in the wall temperature, as noted in Figure 7(a) for the flow rate $60 \mathrm{ml} / \mathrm{min}$ and illustrated by the temperature profile in Figure 6(c), is indicative of the occurrence of CHF with corresponding sharp decreases in the heat transfer coefficients near the exit $(\mathrm{x} / \mathrm{L}=0.9)$ shown in Figure 8. A detailed discussion of the CHF data are available in a separate study [29] by the authors.

\subsection{Pressure Drop}

Figure 13(a) shows pressure drop measurements at the flow rate $60 \mathrm{ml} / \mathrm{min}$ over the entire range of heat fluxes (including single- and two-phase flow). For single-phase flow, the pressure drop decreases with increasing heat flux due to the decrease in liquid viscosity with increasing temperature. As noted earlier, single-phase flow covers a range of heat flux up to $34 \mathrm{~W} / \mathrm{cm}^{2}$ while the flow boiling experiments were started (after the occurrence of boiling incipience) at the heat flux of approximately $27 \mathrm{~W} / \mathrm{cm}^{2}$ at this flow rate. The pressure drop increases almost linearly with increasing heat flux before CHF is reached.

Figure 13(b) includes the pressure drop measurements at all the five flow rates. The trends at all five flow rates are shown to be similar to those discussed for the $60 \mathrm{ml} / \mathrm{min}$ flow rate, with the single-phase 
pressure drop being higher for a higher flow rate. Pressure drop measurements over the heat flux range corresponding to two-phase flow (and prior to CHF) are plotted separately in Figure 13(c) along with a linear curve-fit with $\pm 10 \%$ error bounds. It is clear that throughout the boiling regime, pressure drop has minimal dependence on flow rate due to the balance between acceleration and friction of the fluid. At a fixed heat flux, a larger vapor quality at a lower flow rate gives rise to a larger contribution to the pressure drop from acceleration of the fluid and a smaller contribution from flow friction; the reverse is true at a higher flow rate. It is interesting to note that the time-averaged pressure drop measurements in Figure 13 are not affected by flow instabilities in the microchannels.

\section{Summary and Conclusions}

Flow boiling of a dielectric fluid FC-77 in a silicon microchannel heat sink $(12.7 \mathrm{~mm} \times 12.7 \mathrm{~mm})$ containing 60 parallel microchannels, each $100 \mu \mathrm{m}$ wide and $389 \mu \mathrm{m}$ deep, was investigated. Local heat transfer distributions were measured, along with the pressure drop across the length of the microchannels. The experiments were performed at five flow rates through the heat sink in the range of 20 to $80 \mathrm{ml} / \mathrm{min}$ with a fixed inlet subcooling $26 \mathrm{~K}$ in all cases. At each flow rate, a range of heat fluxes are considered which correspond to single-phase and two-phase flow up to the occurrence of critical heat flux (CHF).

The flow in the downstream region of the microchannels progresses through successive flow patterns as the heat flux is increased: bubbly flow, slug flow, elongated bubble flow or annular flow, alternating wisp-annular/churn flow, and wall dryout. As a result, the heat transfer coefficients in this region experience substantial variations over this heat flux range, based on which five distinct boiling regimes are identified. In contrast, the heat transfer coefficient in the middle region remains relatively constant over the entire heat flux range. The flow in the upstream region, on the other hand, transitions from single-phase flow to pulsating two-phase flow once flow instabilities set in downstream at a heat flux in the range of $30.5-62.3 \mathrm{~W} / \mathrm{cm}^{2}$ depending on the flow rate. One major finding of this work is that, due to changes in flow patterns during flow instabilities, the heat transfer coefficient is enhanced both in the upstream and downstream regions of the microchannels. In the upstream region, the heat transfer enhancement is seen as a decrease in slope of the wall temperatures with increasing heat flux. In the downstream region, the heat transfer coefficients during the period of flow instability tend to remain constant, but would have otherwise decreased with increasing heat flux. This heat transfer enhancement downstream due to flow instability is in contrast to the insensitivity to instabilities of heat transfer coefficients during flow boiling in larger microchannels in a previous study (389 $\mu \mathrm{m}$ wide and $389 \mu \mathrm{m}$ deep). The pressure drop measurements in this work showed that, due to the balance between 
acceleration and friction of the fluid, the pressure drop during two-phase flow in the microchannels increases almost linearly with increasing heat flux and has a minimal dependence on flow rate until the occurrence of CHF.

\section{Acknowledgement}

Financial support for this work from the Indiana $21^{\text {st }}$ Century Research and Technology Fund is gratefully acknowledged. The authors thank Bruce Myers and Darrel Peugh of Delphi Electronics and Safety, Kokomo, Indiana, for providing the silicon test piece used in this work.

\section{References}

[1] C.B. Sobhan, S.V. Garimella, A comparative analysis of studies on heat transfer and fluid flow in microchannels, Microscale Thermophysical Engineering 5 (2001) 293-311.

[2] S.V. Garimella, C.B. Sobhan, Transport in microchannels - a critical review, Annual Review of Heat Transfer 13 (2003) 1-50.

[3] T. Harirchian, S.V. Garimella, A comprehensive flow regime map for microchannel flow boiling with quantitative transition criteria, International Journal of Heat and Mass Transfer 53 (2010) 2694-2702.

[4] J.G. Collier, J.R. Thome, Convective boiling and condensation, 3rd edition, McGraw Hill, New York, 1994.

[5] O. Zurcher, J.R. Thome, D. Favrat, Evaporation of ammonia in a smooth horizontal tube: Heat transfer measurements and predictions, Journal of Heat Transfer 121 (1999) 89-101.

[6] P.A. Kew, K. Cornwell, Correlations for the prediction of boiling heat transfer in small-diameter channels, Applied Thermal Engineering 17 (1997) 705-715.

[7] T. Yen, N. Kasagi, Y. Suzuki, Forced convective boiling heat transfer in microtubes at low mass and heat fluxes, International Journal of Heat and Mass Transfer 29 (2003) 1771-1792.

[8] K.S. Park, W.H. Choo, K.H. Bang, Flow boiling heat transfer of R-22 in small-diameter horizontal round tubes, Proceedings of 1st Int. Conference on Microchannels and Minichannels, Rochester, New York. April 24-25, 2003.

[9] G. Hetsroni, A. Mosyak, Z. Segal, G. Ziskind, A uniform temperature heat sink for cooling of electronic devices, International Journal of Heat and Mass Transfer 45 (2002) 3275-3286.

[10] M. Piasecka, S. Hozejowska, M.E. Poniewski, Experimental evaluation of flow boiling incipience of subcooled flow in a narrow channel, International Journal of Heat and Fluid Flow 25 (2004) 159172.

[11] S.S. Bertsch, E.A. Groll, S.V. Garimella, Refrigerant flow boiling heat transfer in parallel microchannels as a function of local vapor quality, International Journal of Heat and Mass Transfer 51 (2008) 4775-4787.

[12] T. Harirchian, S.V. Garimella, Effects of channel dimension, heat flux, and mass flux on flow boiling regimes in microchannels, International Journal of Heat and Mass Transfer 35 (2009) 349-362. 
[13] T. Harirchian, S.V. Garimella, Microchannel size effects on local flow boiling heat transfer to a dielectric fluid, International Journal of Heat and Mass Transfer 51 (2008) 3724-3735.

[14] T.G. Karayiannis, D. Shiferaw, D.R. Kenning, V.V. Wadekar, Flow patterns and heat transfer for flow boiling in small to micro diameter tubes, Heat Transfer Engineering 31(2010) 257-275.

[15] W. Qu, I. Mudawar, Transport phenomena in two-phase micro-channel heat sinks, Journal of Electronic Packaging 126 (2004) 213-224.

[16] D. Brutin, L. Tadrist, Measurement and prediction of pressure drop in two-phase microchannel heat sinks, International Journal of Heat and Mass Transfer 46 (2003) 2737-2753.

[17] H.Y. Wu, P. Cheng, Boiling instability in parallel silicon microchannels at different heat flux, International Journal of Heat and Mass Transfer 47 (2004) 3631-3641.

[18] G. Hetsroni, A. Mosyak, Z. Segal, Non-uniform temperature distribution in electronic devices cooled by flow in parallel microchannels, IEEE Transactions on Components and Packaging Technology 24 (1) (2001) 16-23.

[19] T. Chen, S.V. Garimella, Measurements and high-speed visualizations of flow boiling of a dielectric fluid in a silicon microchannel heat sink, International Journal of Multiphase Flow 32 (2006) 957-971.

[20] C. Gillot, L. Meysenc, C. Schaeffer, Integrated single and two-phase micro heat sinks under IGBT chips, IEEE Transactions on Components and Packaging Technology 22(3) (1999) 384-389.

[21] T. Chen, S.V. Garimella, Flow boiling heat transfer to a dielectric fluid in a microchannel heat sink, IEEE Transactions on Components and Packaging Technologies 30(1) (2007) 24-31.

[22] M.G. Cooper, Heat flow rates in saturated nucleate pool boiling - a wide ranging examination using reduced properties, Adv. Heat Transfer 16 (1984) 157-239.

[23] S.S. Bertsch, E.A. Groll, S.V. Garimella, A composite heat transfer correlation for saturated flow boiling in small channels, International Journal of Heat and Mass Transfer 52 (2009) 2110-2118.

[24] T. Chen, S.V. Garimella, Effects of dissolved air on subcooled flow boiling of a dielectric coolant in a microchannel heat sink, Journal of Electronic Packaging 128 (2006) 398-404.

[25] S.J. Kline, F.A. McClintock, Describing uncertainties in single-sample experiments, Mechanical Engineering, vol. 75, 3-8, 1953.

[26] S.G. Kandlikar, Similarities and differences between flow boiling in microchannels and pool boiling, Heat Transfer Engineering 31(3) (2010) 159-167.

[27] A. Jacobi, J.R. Thome, Heat transfer model for evaporation of elongated bubble flows in microchannels, Journal of Heat Transfer 124 (2002) 1131-1136.

[28] J.R. Thome, L. Consolini, Mechanisms of boiling in micro-channels: critical assessment, Heat Transfer Engineering 31(4) (2010) 288-297.

[29] T. Chen, S.V. Garimella, A study of critical heat flux during flow boiling in microchannel heat sinks, Proceedings of the $8^{\text {th }}$ ASME-JSME Thermal Engineering Conference, Honolulu, Hawaii, March 13-17, 2011. 


\section{List of Figures}

Figure Error! Main Document Only.. Experimental test loop.

Figure Error! Main Document Only.. (a) Photograph of the printed circuit board (PCB) with the silicon die at the center, and (b) mounting details of the silicon die on the PCB.

Figure Error! Main Document Only.. (a) The arrangement of 25 heating elements U1-U25 (not shown in the figure are 25 diode temperature sensors, each located at the center of each heating element); (b) photograph of the test section assembly ('A' and 'B' are fluid inlet and outlet, 'C' and 'D' are thermocouple insertion ports, and ' $\mathrm{E}$ ' and ' $\mathrm{F}$ ' are connected to the differential pressure transducer).

Figure Error! Main Document Only.. (a) Calibrated voltage-temperature dependence for the 25 temperature sensors, and (b) calibrated electrical resistances of the 25 heating elements on the test chip.

Figure Error! Main Document Only.. (a) Wall temperatures measured by the five temperature sensors located along the midline of the heat $\operatorname{sink}(\mathrm{x} / \mathrm{L}=0.1$ nearest to the inlet and $\mathrm{x} / \mathrm{L}=0.9$ nearest to the exit) at the flow rate $60 \mathrm{ml} / \mathrm{min}$; after boiling is initiated (with a small increase in heat flux from the point labeled 'A'), the heat input is decreased to $27 \mathrm{~W} / \mathrm{cm}^{2}$ (labeled 'B'); (b) wall temperatures at $\mathrm{x} / \mathrm{L}=0.9$ with the arrows indicating the chronological order in which the heat input was applied.

Figure Error! Main Document Only.. Wall temperature distributions $\left({ }^{\circ} \mathrm{C}\right)$ measured in the heat sink under three different conditions at a flow rate $60 \mathrm{ml} / \mathrm{min}$ : (a) prior to boiling initiation (heat flux of 33.96 $\mathrm{W} / \mathrm{cm}^{2}$ ), (b) after boiling initiation (heat flux of $33.66 \mathrm{~W} / \mathrm{cm}^{2}$ ), and (c) when CHF occurs (heat flux of $\left.86.7 \mathrm{~W} / \mathrm{cm}^{2}\right)$. The flow is in the direction from right to left.

Figure Error! Main Document Only.. Heat transfer measurements at the flow rate $60 \mathrm{ml} / \mathrm{min}$ : (a) streamwise wall temperatures, (b) heat transfer coefficients downstream and in the middle region.

Figure Error! Main Document Only.. Local heat transfer coefficients measured near the exit at $\mathrm{x} / \mathrm{L}=0.9$ at the five flow rates.

Figure Error! Main Document Only.. Visualization results showing the development of flow patterns with increasing heat flux in the boiling regimes ' $a$ ' and ' $b$ ' at the flow rate of $60 \mathrm{ml} / \mathrm{min}$.

Figure Error! Main Document Only.. Flow visualization showing the vapor core and extended wall dryout during wispy-annular flow near the exit of the microchannels (flow rate $=60 \mathrm{ml} / \mathrm{min}$, heat flux $=$ $\left.65 \mathrm{~W} / \mathrm{cm}^{2}\right)$.

Figure Error! Main Document Only.. (a) Pressure drop measurements across the microchannels at four heat flux levels at a flow rate of $60 \mathrm{ml} / \mathrm{min}$ showing the pressure drop fluctuations, and (b) standard deviations of the pressure drop fluctuations at the five flow rates. 
Figure Error! Main Document Only.. Wall temperature measured near the inlet at $\mathrm{x} / \mathrm{L}=0.1$ and heat transfer coefficients measured near the exit at $\mathrm{x} / \mathrm{L}=0.9$; for each flow rate, label ' $\mathrm{Q}$ ' corresponds to the heat flux at which a decrease in the slope of the wall temperature upstream is noted.

Figure Error! Main Document Only.. Pressure drop measurements over the entire heat flux range for both single-phase and two-phase flow: (a) at the flow rate of $60 \mathrm{ml} / \mathrm{min}$, (b) at all five flow rates, and (c) linear curve-fit of measured pressure drop at the five flow rates in the two-phase flow regime prior to CHF. 


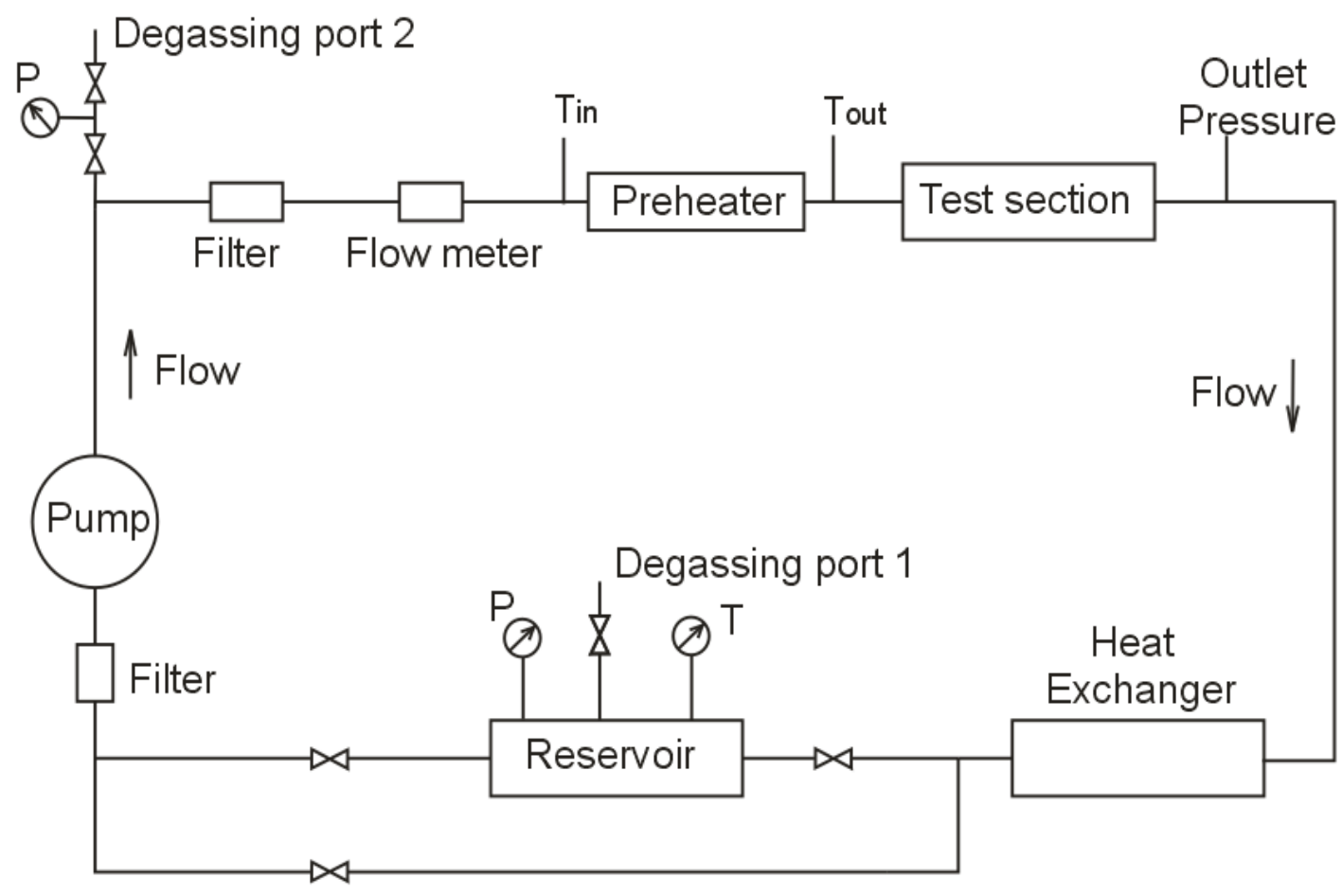

Figure Error! Main Document Only.. Experimental test loop. 


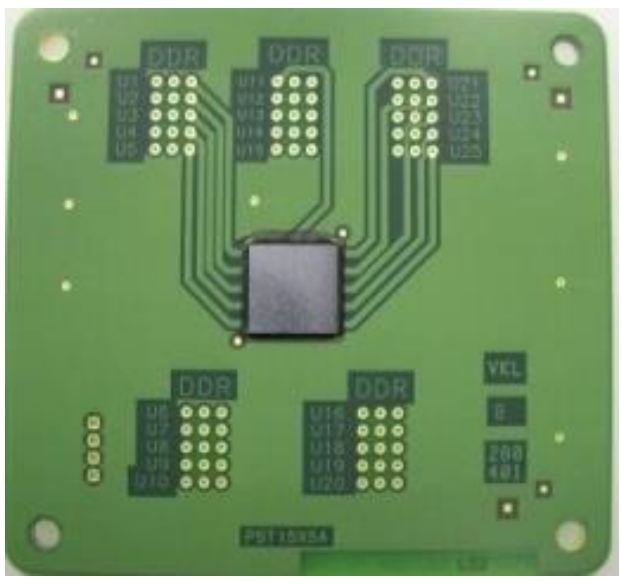

(a)

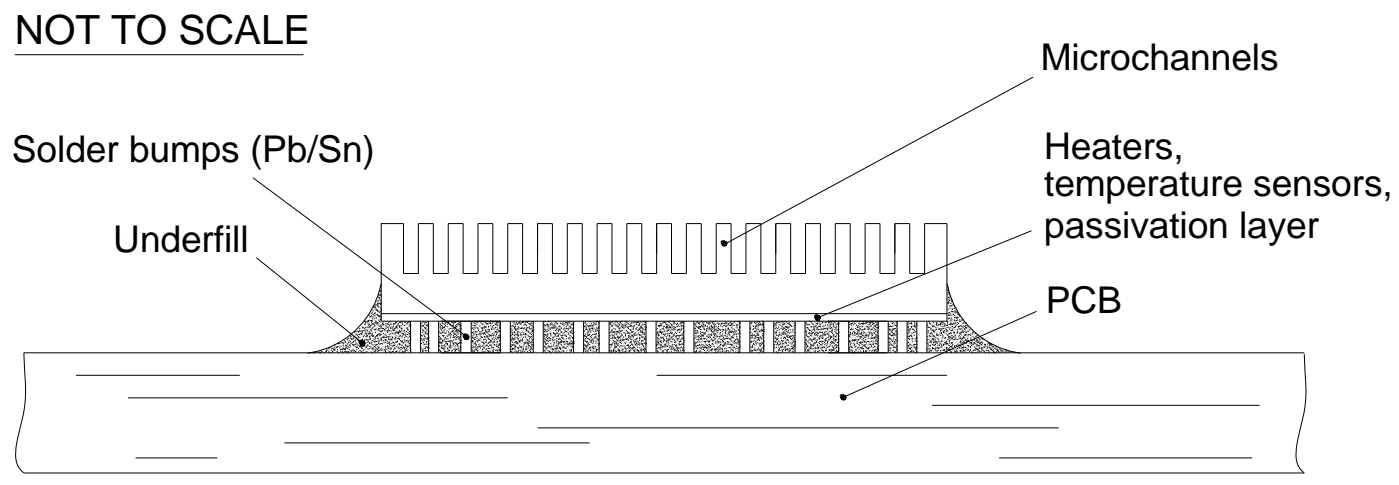

(b)

Figure Error! Main Document Only.. (a) Photograph of the printed circuit board (PCB) with the silicon die at the center, and (b) mounting details of the silicon die on the PCB. 


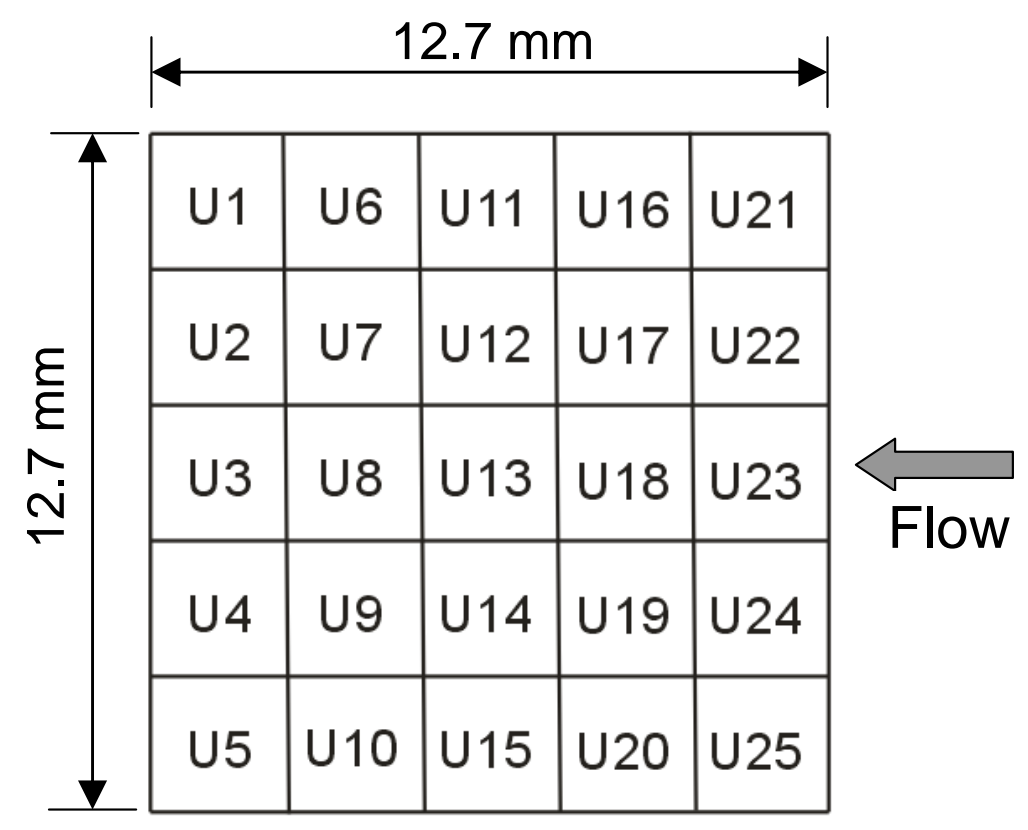

(a)

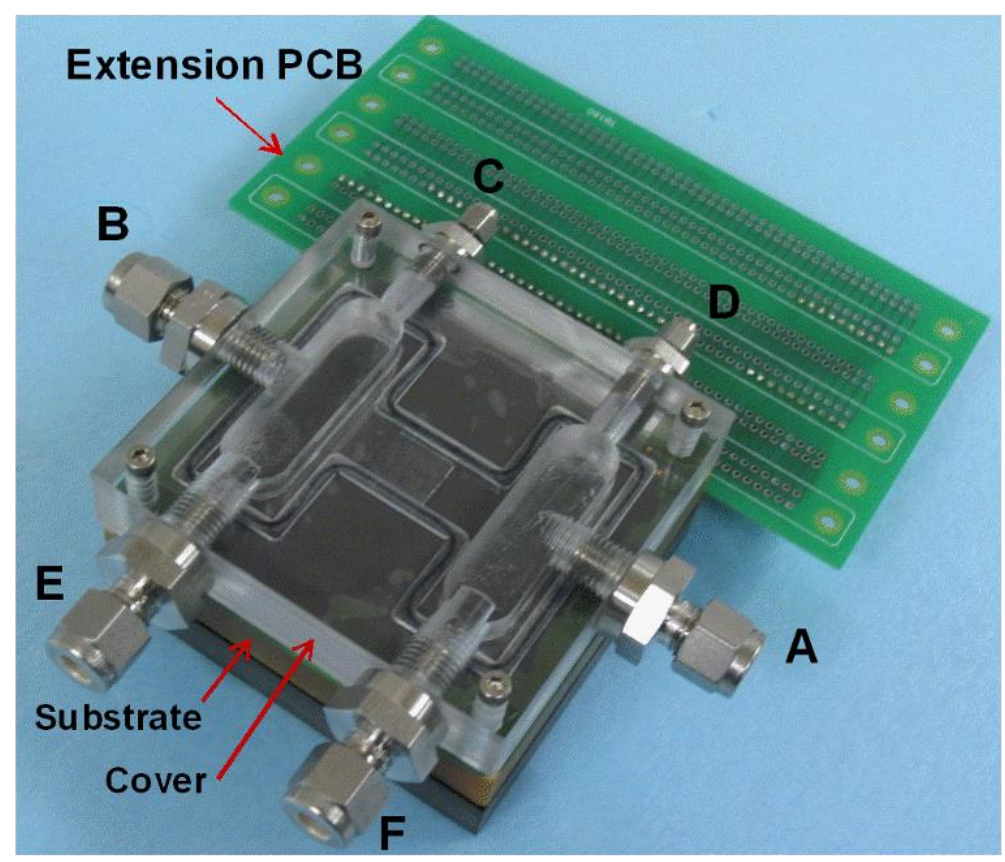

(b)

Figure Error! Main Document Only.. (a) The arrangement of 25 heating elements U1-U25 (not shown in the figure are 25 diode temperature sensors, each located at the center of each heating element); (b) photograph of the test section assembly ('A' and 'B' are fluid inlet and outlet, ' $C$ ' and ' $D$ ' are thermocouple insertion ports, and ' $\mathrm{E}$ ' and ' $\mathrm{F}$ ' are connected to the differential pressure transducer). 


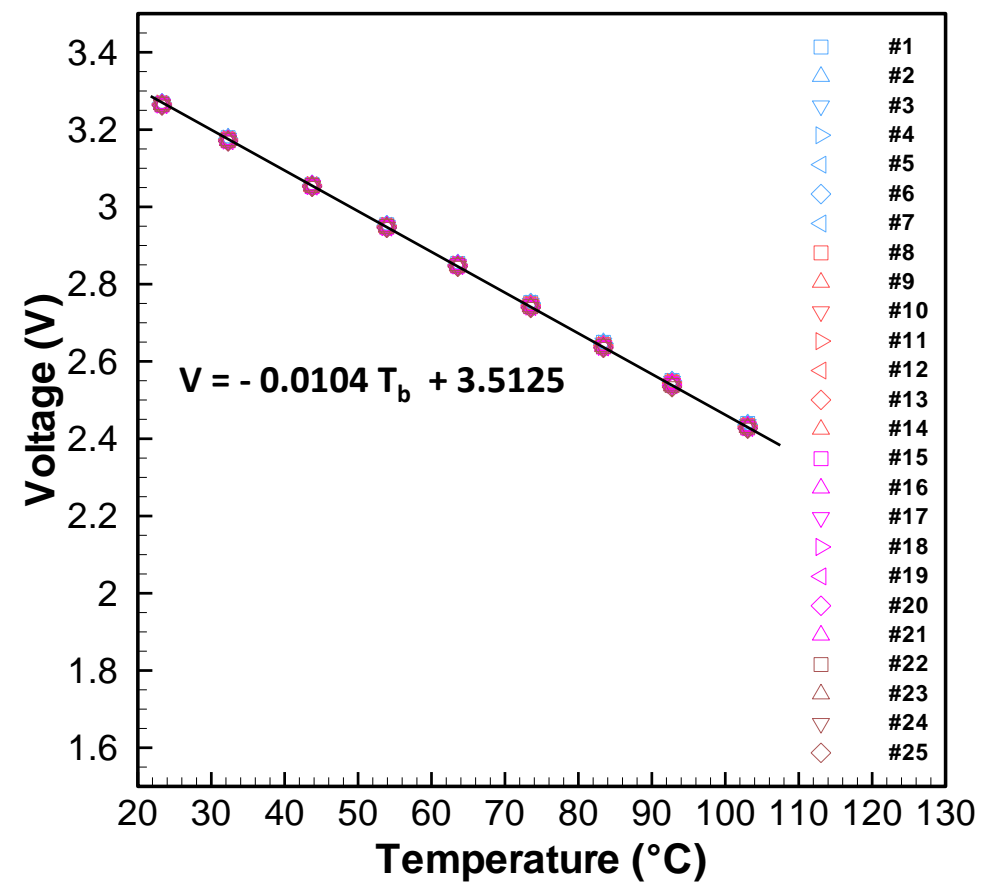

(a)

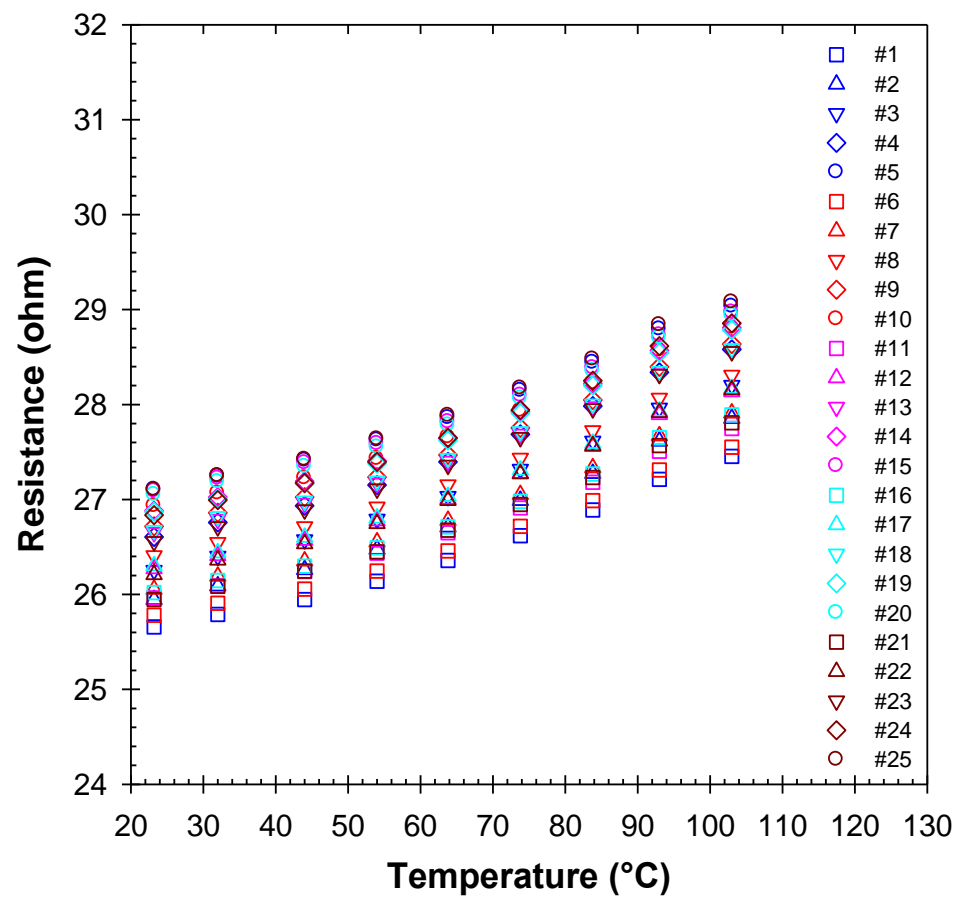

(b)

Figure Error! Main Document Only. (a) Calibrated voltage-temperature dependence for the 25 temperature sensors, and (b) calibrated electrical resistances of the 25 heating elements on the test chip. 


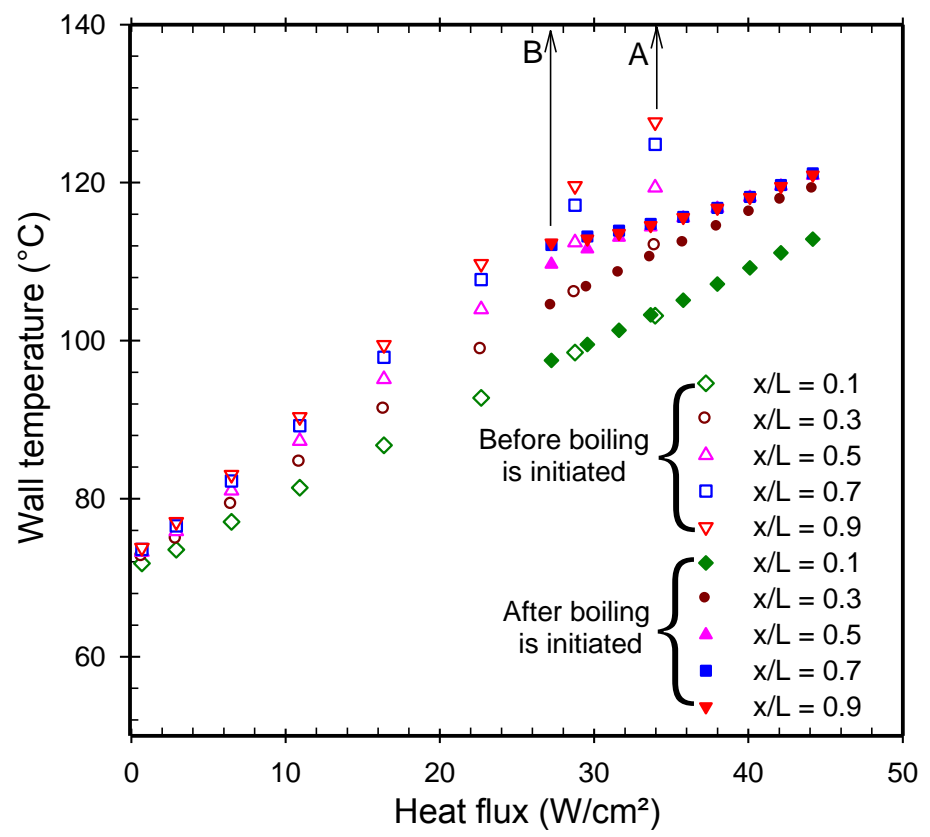

(a)

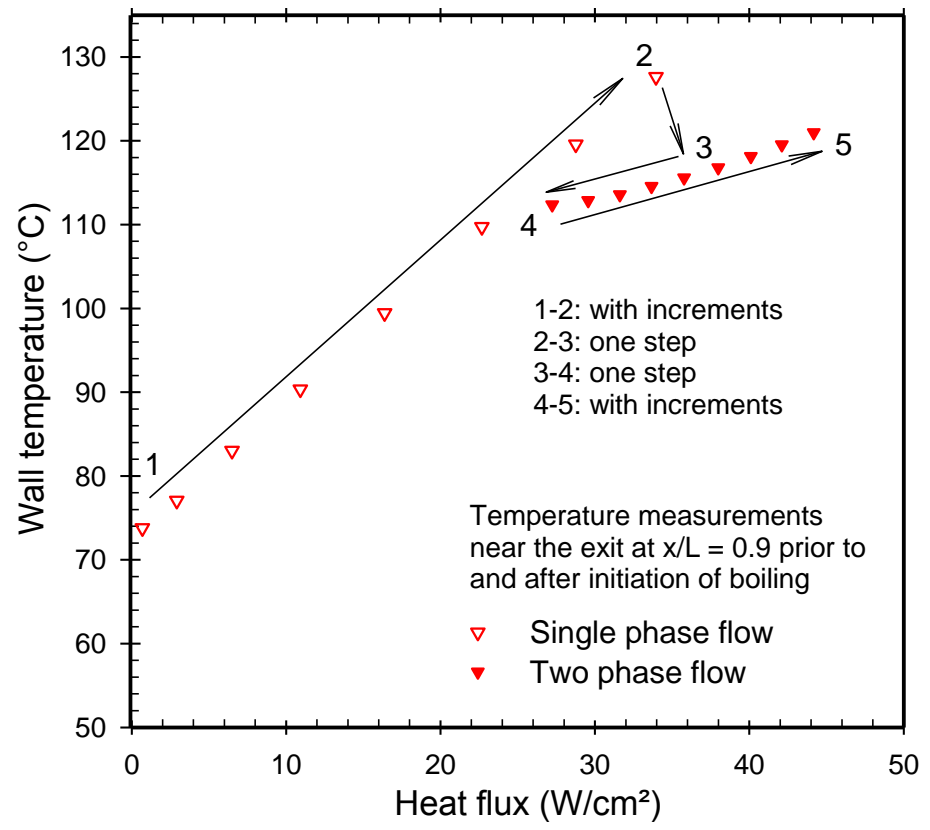

(b)

Figure Error! Main Document Only. (a) Wall temperatures measured by the five temperature sensors located along the midline of the heat $\operatorname{sink}(\mathrm{x} / \mathrm{L}=0.1$ nearest to the inlet and $\mathrm{x} / \mathrm{L}=0.9$ nearest to the exit) at the flow rate $60 \mathrm{ml} / \mathrm{min}$; after boiling is initiated (with a small increase in heat flux from the point labeled ' $A$ '), the heat input is decreased to $27 \mathrm{~W} / \mathrm{cm}^{2}$ (labeled ' $\mathrm{B}$ '); (b) wall temperatures at $\mathrm{x} / \mathrm{L}=0.9$ with the arrows indicating the chronological order in which the heat input was applied. 


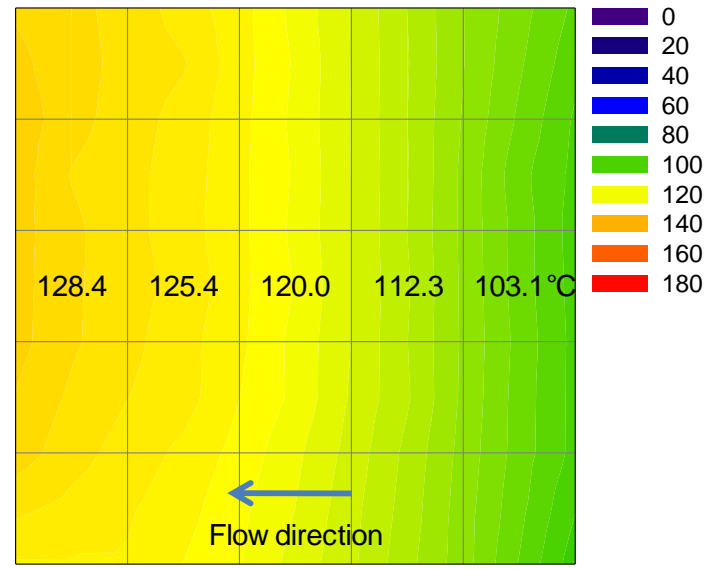

(a)

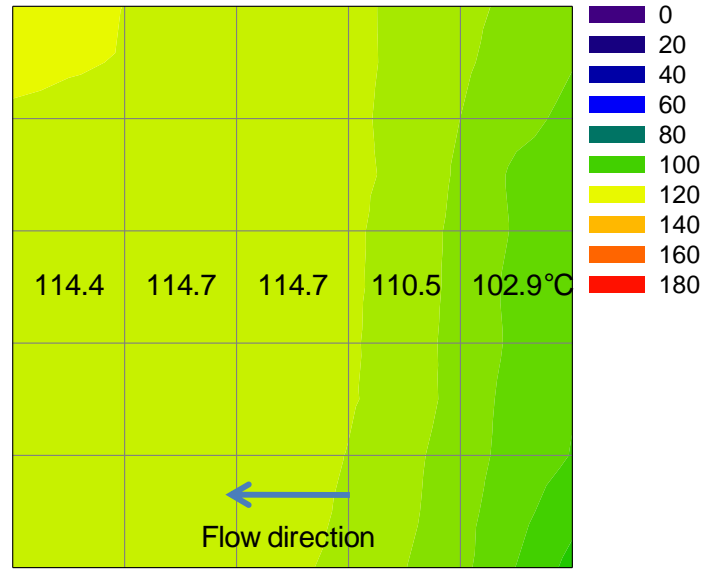

(b)

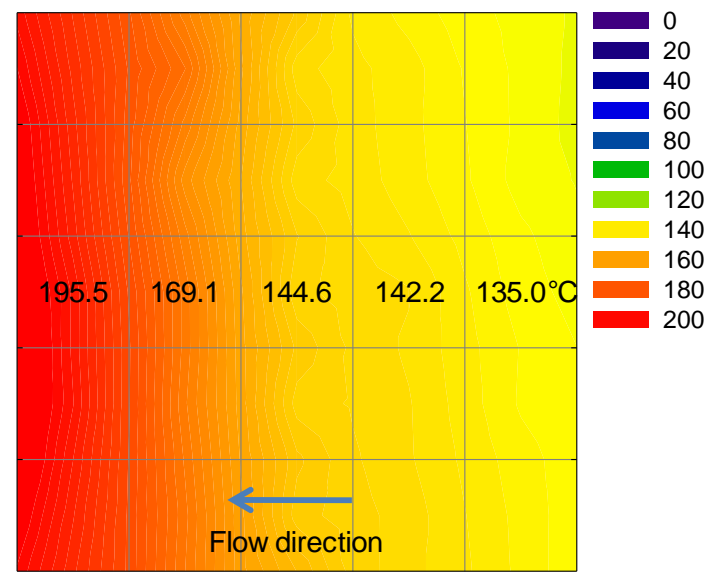

(c)

Figure Error! Main Document Only.. Wall temperature distributions $\left({ }^{\circ} \mathrm{C}\right)$ measured in the heat sink under three different conditions at a flow rate $60 \mathrm{ml} / \mathrm{min}$ : (a) prior to boiling initiation (heat flux of 33.96 $\mathrm{W} / \mathrm{cm}^{2}$ ), (b) after boiling initiation (heat flux of $33.66 \mathrm{~W} / \mathrm{cm}^{2}$ ), and (c) when CHF occurs (heat flux of $\left.86.7 \mathrm{~W} / \mathrm{cm}^{2}\right)$. The flow is in the direction from right to left. 


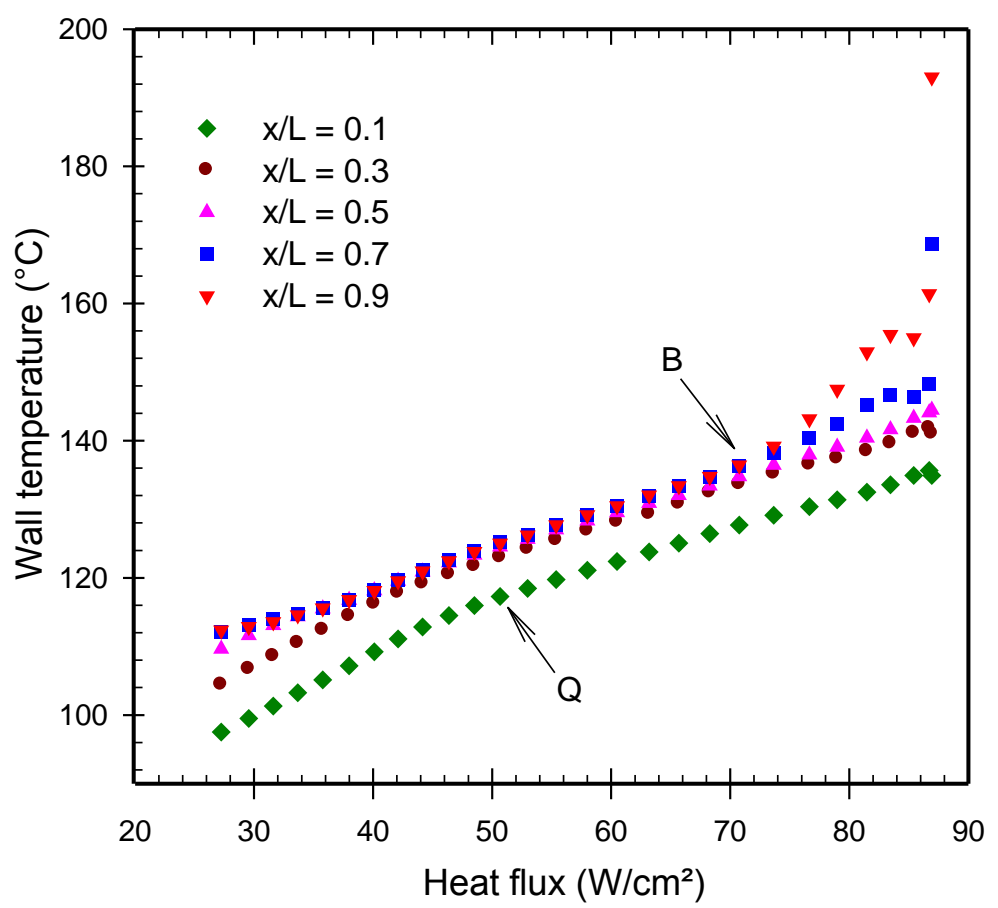

(a)

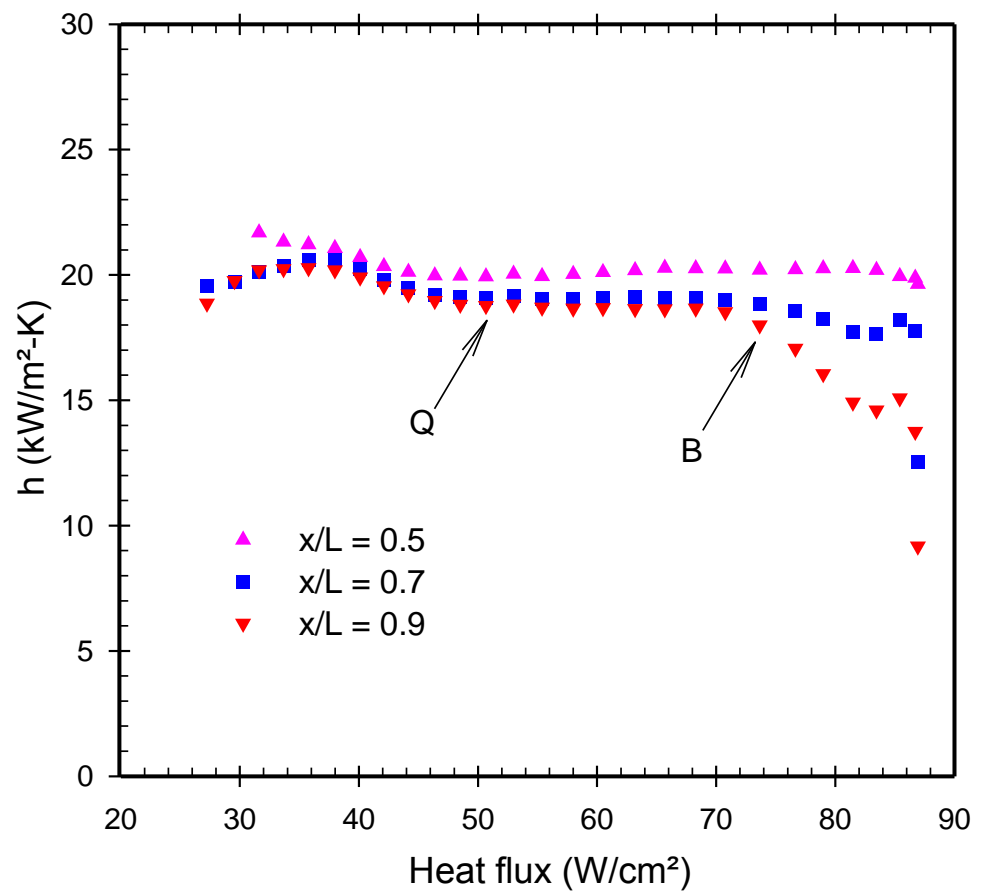

(b)

Figure Error! Main Document Only.. Heat transfer measurements at the flow rate $60 \mathrm{ml} / \mathrm{min}$ : (a) stream-wise wall temperatures, (b) heat transfer coefficients downstream and in the middle region. 


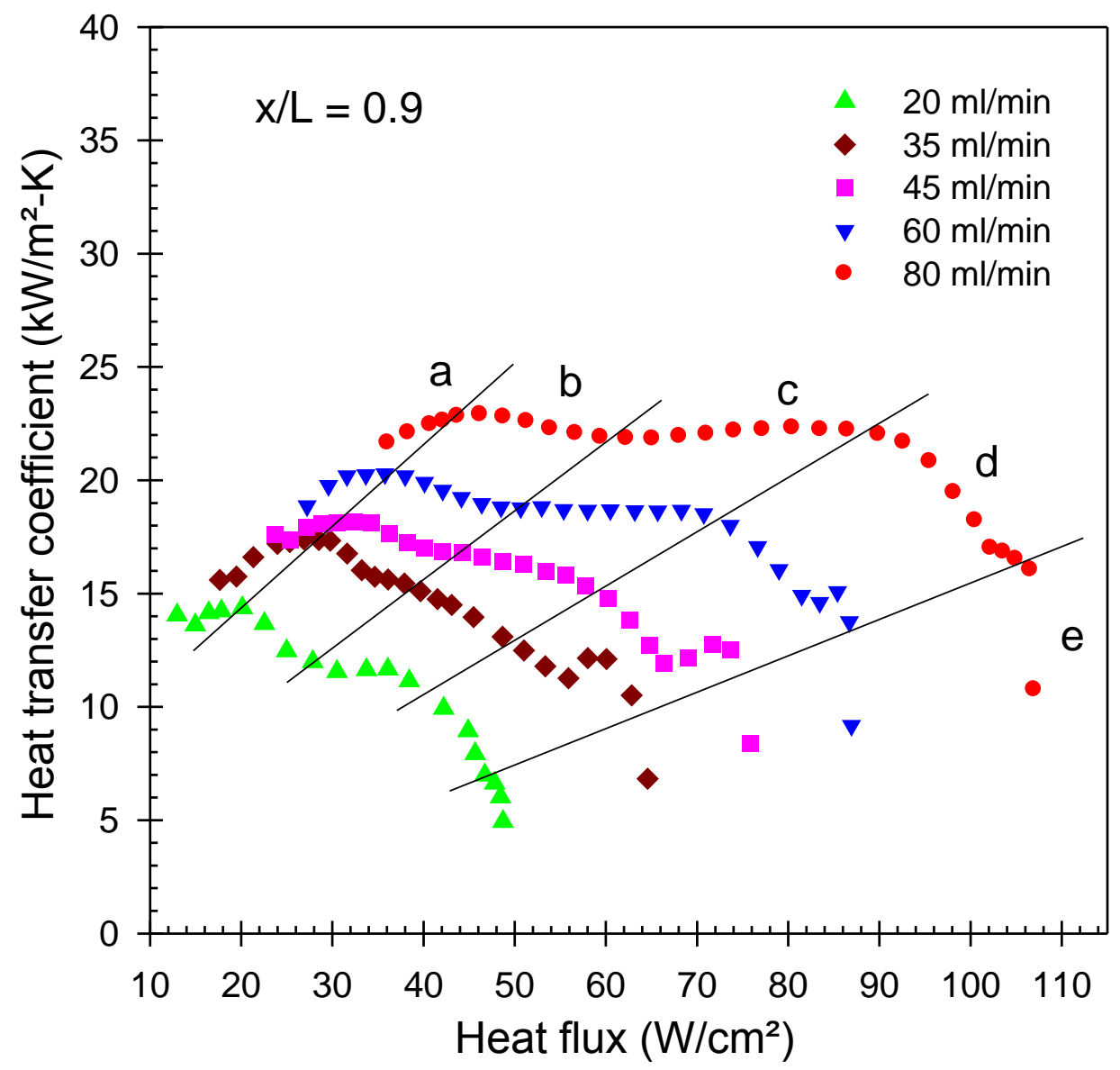

Figure Error! Main Document Only.. Local heat transfer coefficients measured near the exit at $\mathrm{x} / \mathrm{L}=$ 0.9 at the five flow rates. 


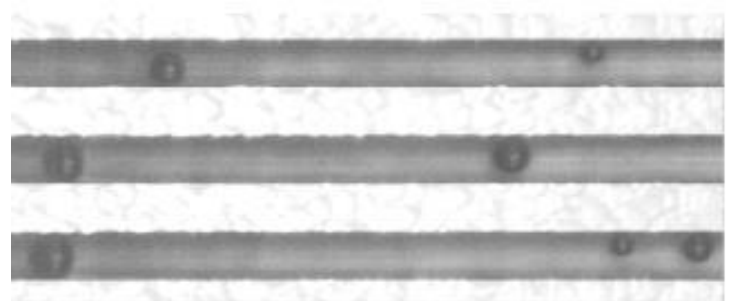

Bubbly flow: $27.2 \mathrm{~W} / \mathrm{cm}^{2}$

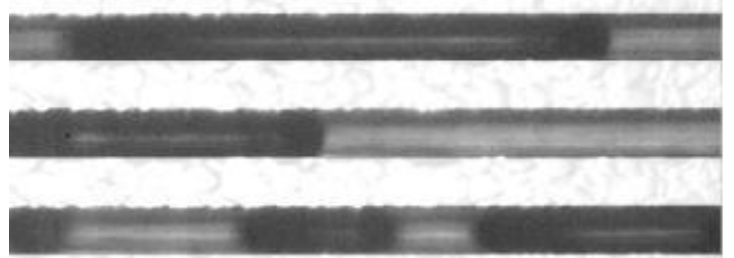

Elongated slugs: $35.8 \mathrm{~W} / \mathrm{cm}^{2}$

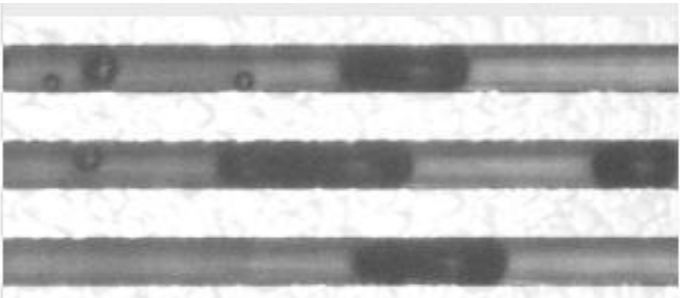

Slug flow: $31.6 \mathrm{~W} / \mathrm{cm}^{2}$

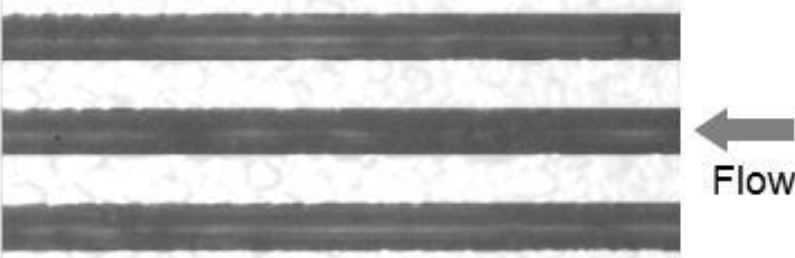

Annular flow: $42.1 \mathrm{~W} / \mathrm{cm}^{2}$

Figure Error! Main Document Only.. Visualization results showing the development of flow patterns with increasing heat flux in the boiling regimes ' $a$ ' and ' $b$ ' at the flow rate of $60 \mathrm{ml} / \mathrm{min}$. 


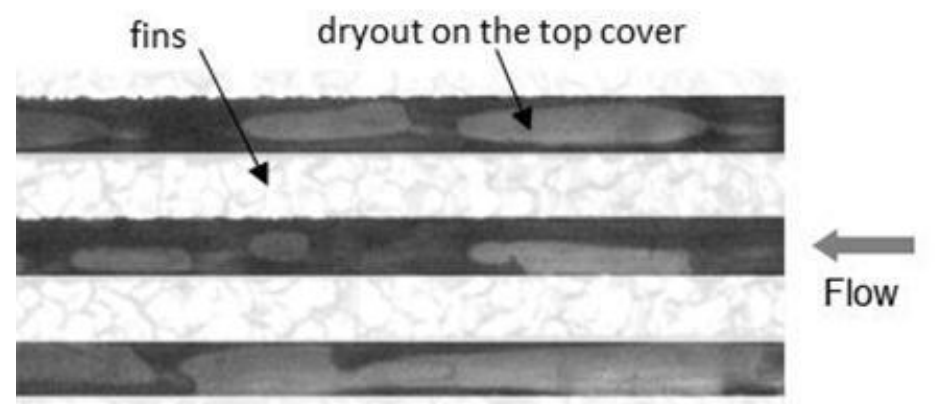

Figure Error! Main Document Only.. Flow visualization showing the vapor core and extended wall dryout during wispy-annular flow near the exit of the microchannels (flow rate $=60 \mathrm{ml} / \mathrm{min}$, heat flux $=$ $\left.65 \mathrm{~W} / \mathrm{cm}^{2}\right)$. 


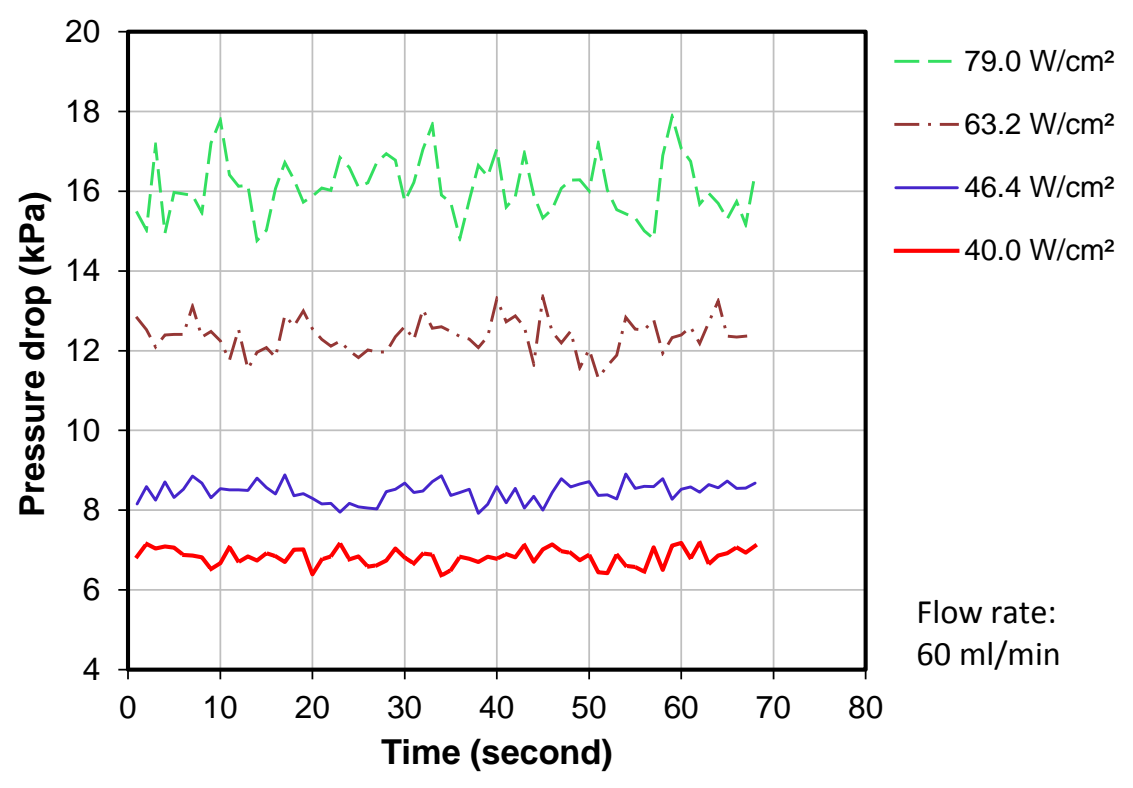

(a)

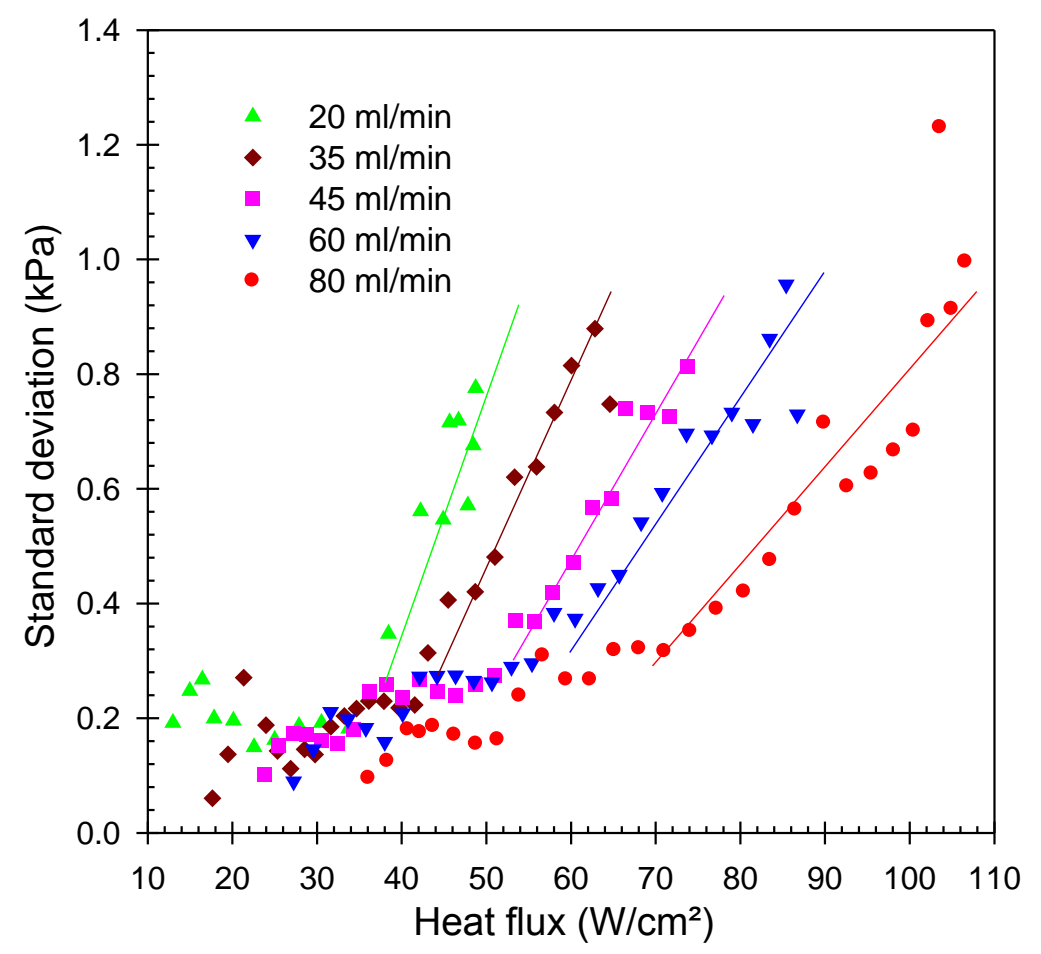

(b)

Figure Error! Main Document Only.. (a) Pressure drop measurements across the microchannels at four heat flux levels at a flow rate of $60 \mathrm{ml} / \mathrm{min}$ showing the pressure drop fluctuations, and (b) standard deviations of the pressure drop fluctuations at the five flow rates. 

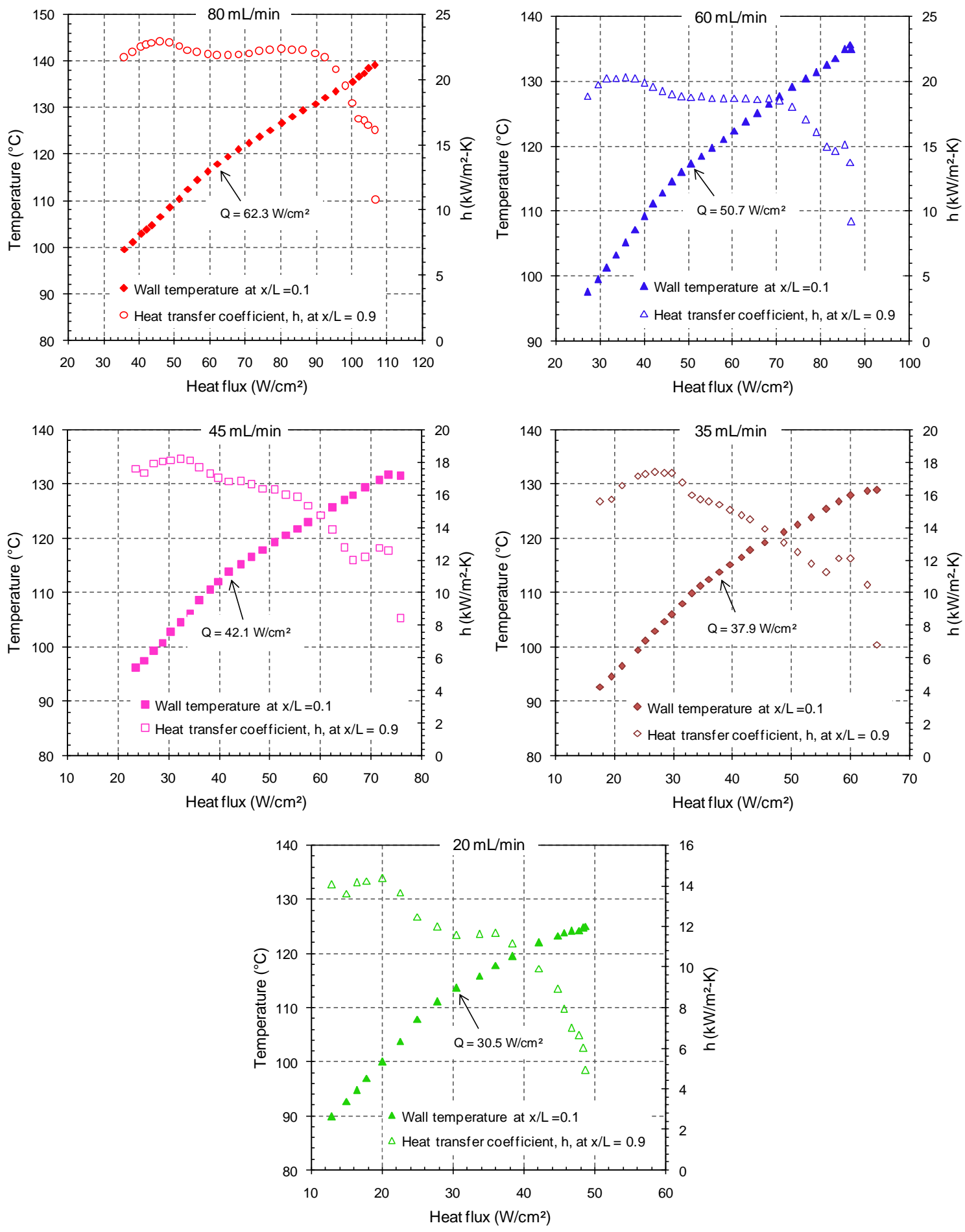

Figure Error! Main Document Only.. Wall temperature measured near the inlet at $\mathrm{x} / \mathrm{L}=0.1$ and heat transfer coefficients measured near the exit at $\mathrm{x} / \mathrm{L}=0.9$; for each flow rate, label ' $\mathrm{Q}$ ' corresponds to the heat flux at which a decrease in the slope of the wall temperature upstream is noted. 


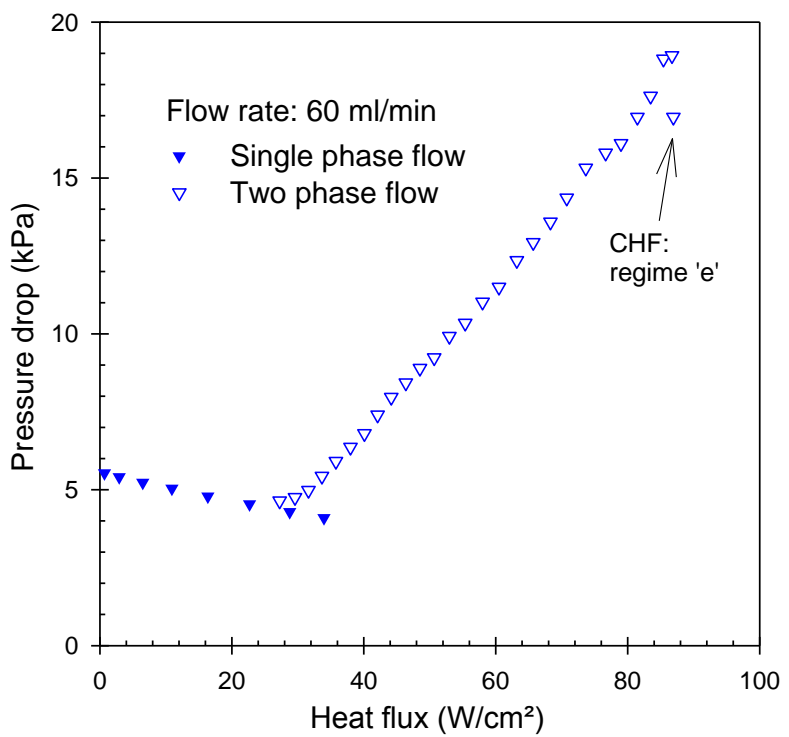

(a)

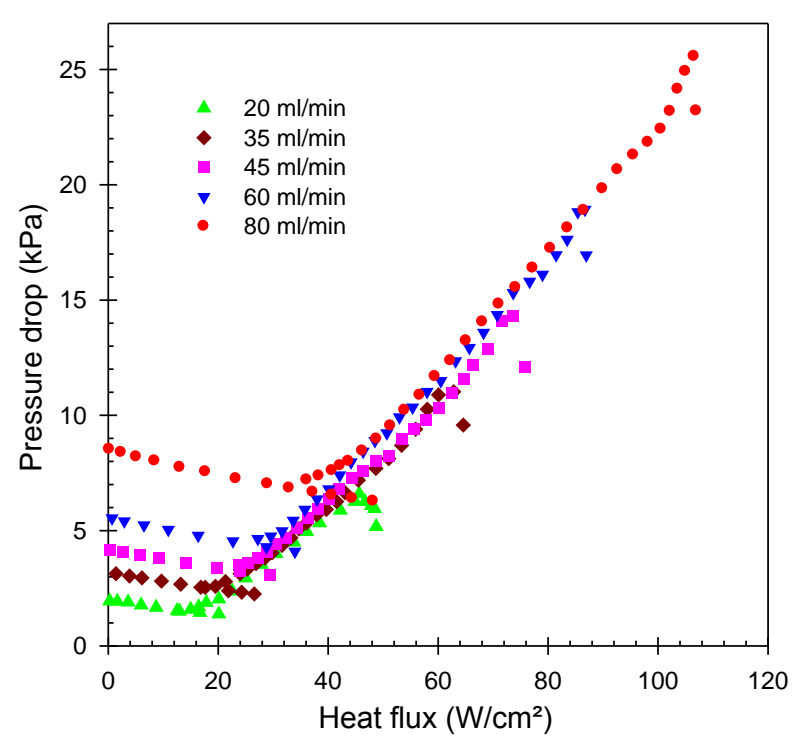

(b)

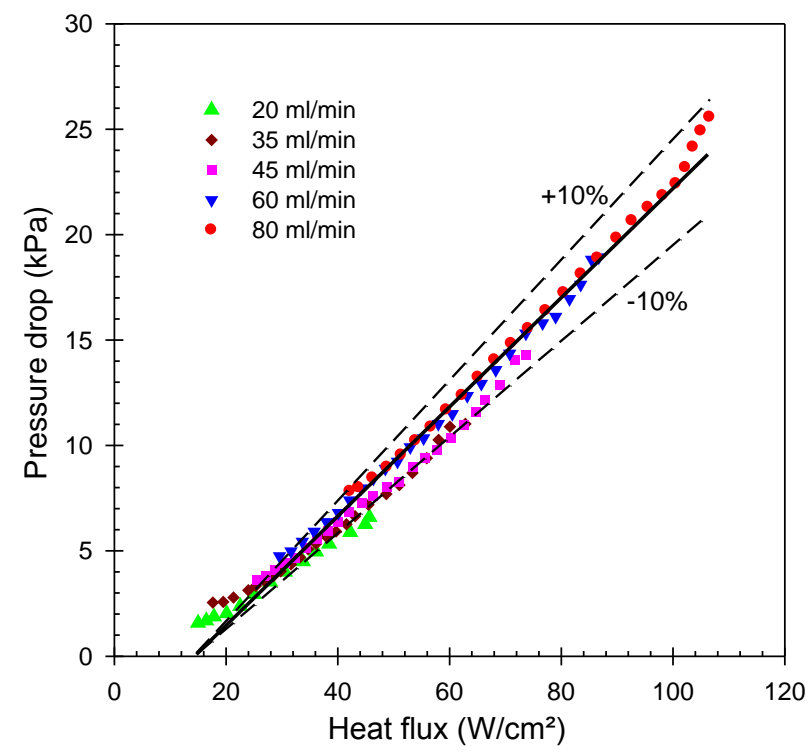

(c)

Figure Error! Main Document Only.. Pressure drop measurements over the entire heat flux range for both single-phase and two-phase flow: (a) at the flow rate of $60 \mathrm{ml} / \mathrm{min}$, (b) at all five flow rates, and (c) linear curve-fit of measured pressure drop at the five flow rates in the two-phase flow regime prior to CHF. 